\title{
Ameiridae Boeck and Argestidae Por revisited, with establishment of Parameiropsidae, a new family of Harpacticoida (Crustacea, Copepoda) from deep-sea sediments
}

\author{
P. H. C. Corgosinho - P. Martínez Arbizu
}

Received: 25 February 2009 / Revised: 19 November 2009 / Accepted: 16 December 2009 / Published online: 6 January 2010 (C) Springer-Verlag and AWI 2010

\begin{abstract}
Four new species of Parameiropsis are described from Angola and Guinea Basins and the Arctic Laptev Sea. The male of Parameiropsis poseidonicus sp. $\mathrm{n}$. differs from that of $P$. neptuni sp. n. and $P$. senckenbergi $\mathrm{sp}$. $\mathrm{n}$. in antennule segmentation, length of the proximal aesthetasc, length of the outermost seta of the antennary endopod, degree of reduction of the mouthparts, relative length of the inner spine of the basis of thoracopod 1, shape of the furca and body length. The female of $P$. amphitriteae sp. n. differs from previously described females of other species in the smaller exopod and endpod of thoracopod 1, reduced armature of thoracopods 1-6, length of the outer setae of exopods and endopods of thoracopods 2-4, and mandible exopod weakly developed and fused to the basis. Parameiropsis is redefined by the following autapomorphies: presence of aesthetasc on 3rd segment of female antennule; antenna strong, with endopod curved upwardly, and shape of the outermost (strongly ornamented) spine; triangular
\end{abstract}

Communicated by Peter Funch.

P. H. C. Corgosinho $(\varangle) \cdot$ P. Martínez Arbizu

Forschungsinstitut Senckenberg, Abt. DZMB (Deutsches Zentrum für Marine Biodiversitätsforschung), Südstrand 44,

26382 Wilhelmshaven, Germany

e-mail: pcorgo@yahoo.com.br

P. Martínez Arbizu

e-mail:pmartinez@senckenberg.de

\section{P. H. C. Corgosinho}

Department of Biology, Universidade Estadual de Montes Claros,

Minas Gerais, Brazil

P. Martínez Arbizu

Fakultät V, Institut für Biologie und Umweltwissenschaften,

Universität Oldenburg, Oldenburg, Germany labrum; elongated corpus mandibularis, gnathobasis very long; basis of mandibular palp unarmed; elongated maxillule, with long and flexible setae on praecoxal arthrite; basis of the maxilla with strongly modified claw. To discuss the phylogenetic position of Parameiropsis, we revaluated the subfamilies of Ameiridae (viz. Ameirinae and Stenocopiinae) and the family Argestidae. Anoplosomella and Malacopsyllus revealed to be not closely related to Ameiridae and are transferred to Argestidae, sharing with other members of this family the morphology of the mandible gnathobasis, armature of maxilla and armature and length of the first segment of the antennule. Argestoides prehensilis does not show any of the characters that we consider autapomorphic for Argestidae. Instead, it shows many characters in common with several Ameiridae species. Parameiropsis does not have any character that could justify its inclusion within Ameiridae or even within Podogennonta. It also cannot be included satisfactorily within Argestidae nor Exanechentera. Therefore, we here propose a new family for Parameiropsis, with unclear relationships within Harpacticoida. After these taxonomic rearrangements, Ameiridae and Argestidae are considered monophyletic based on certain maxilla characters that we consider autapomorphic for each group. A key to the identification of the known species of Parameiropsis is added at the end.

Keywords Ameiridae $\cdot$ Argestidae $\cdot$ Deep sea .

New species $\cdot$ Parameiropsis $\cdot$ Parameiropsidae fam. $\mathrm{n}$

\section{Introduction}

The knowledge about the monophyly and the phylogenetic position of many taxa within Harpacticoida is in a state of flux (e.g. Fiers 1990; Huys 1990; Martínez Arbizu and 
Moura 1994; Huys and Lee 1998; Willen 2000; Lee and Huys 2002; Seifried 2003; Seifried and Schminke 2003; Huys and Conroy-Dalton 2006; Huys et al. 2009). Recently, different researchers have disagreed about the total number of families within this order. For example, Martin and Davis (2001), Seifried (2003), Boxshall and Halsey (2004) and Wells (2007) recognized 54, 51, 52 and 54 families, respectively. Several factors can be responsible for such taxonomic discrepancies. We can mention the method of study adopted by different researchers (namely, the pure application of alpha taxonomy or the phylogenetic classification based on morphological and/or molecular data) and the weight given to distinct characters. Such different application of methods resulted in the splitting and lumping of different taxa. As pointed out by Huys et al. (1996), in what concerns the Harpacticoida familial classification, "many changes are likely to occur in the near future".

Ameiridae Boeck, 1865 and Argestidae Por, 1986 are considered examples of problematic taxa of an unclear monophyletic condition and a confuse taxonomy among the composing genera. The monophyly and the species' composition of Argestidae, since the establishment of this family by Por (1986) have been questioned by different researchers (Fiers 1987; Huys et al. 1996; Bodin 1997; Huys and Conroy-Dalton 1997; Boxshall and Halsey 2004; George 2004, 2008; Wells 2007; Menzel and George 2009).

Ameiridae is considered as much as a monophyletic group (Lee and Huys 2002; Boxshall and Halsey 2004), a polyphyletic group (Fiers 1990; Martínez Arbizu and Moura 1994) or a paraphyletic group (Huys et al. 2009), and the taxonomy at the genus level has already been deemed as a taxonomic nightmare (Conroy-Dalton and Huys 1997).

Recently, Huys et al. (2009) have questioned the monophyly of both Argestidae and Ameiridae. In accordance with the authors, the family Ameiridae would become monophyletic only after the Argestidae genus Argestigens Willey, 1935 and the species composing the family Cancrincollidae Fiers, 1990 are transferred to it. We do not agree with some of Huys et al. (2009) conclusions, and a discussion is given along the text.

Species of Parameiropsis Becker, 1974 (viz. P. peruanus Becker, 1974 and P. rapiens Becker 1974) were firstly described by Becker (1974), from abyssal sites in the Peru Trench (eastern Pacific Ocean) and from the North-African deep sea (on the Atlantic coast). Becker (1974) justified the placement of this genus within Ameiridae, given some similarities shared by Parameiropsis and Ameiropsis Sars, 1907. A third species (P. magnus Itô, 1983) from southeast off Mindanao Island (Philippines) was described by Itô (1983), who accepted Becker (1974) classification. Finally, a new species ( $P$. antennafortis Corgosinho and Gheerardyn,
2009) was also found in cold-water coral gravel sands in the Porcupine Seabight (NE Atlantic Ocean) (Corgosinho and Gheerardyn 2009).

Towards a revision of the family Ameiridae, four new species of the genus Parameiropsis are described here in. The males are described for the first time, the position of Parameiropsis within Ameiridae is questioned, and a new family is created to accommodate this genus.

The subfamilies Ameirinae Lang, 1944 and Stenocopiinae were re-evaluated. The subfamily Stenocopiinae Lang, 1944 is considered polyphyletic. Consequently, Anoplosomella Strand, 1929 and Malacopsyllus Sars, 1911 are transferred to Argestidae based on some putative autapomorphic characters. Argestidae and Ameiridae are redefined.

\section{Materials and methods}

Sediment samples were obtained at depths of about 5,000 $\mathrm{m}$ in Angola and Guinea Basins (SE Atlantic Ocean), during the expeditions DIVA-1 and DIVA-2. Also, sediment samples were obtained from the Laptev Sea (Arctic Ocean), at a depth of $1,100 \mathrm{~m}$ during the TRANSDRIFT I expedition in 1993 (as part of the samples taken during the Russian-German ARCTIC '93 Expedition). Sediment samples were fixed in $4 \%$ formalin on board. In the laboratory, the fixed samples were washed through a $40-\mu \mathrm{m}$ mesh sieve with tap water. Meiofauna and organic material were extracted from remaining sand particles by centrifugation with a colloidal silica polymer (Levasil) as flotation medium and kaolin to cover the heavier particles (McIntyre and Warwick 1984). After centrifugation, the floating matter was decanted and rinsed with tap water and stained with Rose Bengal. Afterwards, copepods were sorted under a stereomicroscope Leica MZ12.5 and transferred to depression slides with glycerine for identification to family level.

Parameiropsis species were dissected in lactic acid and mounted on slides with glycerine. Drawings were made with a Leica DMR microscope equipped with Normarsky interference contrast and a drawing tube, at $400 \times$ and $1000 \times$ magnification.

The term groundpattern is used in the sense of "Grundmuster" (Ax 1984).

The terms 'furca' and 'telson' are used according to Schminke (1976). Terminology and homologization of maxillary and maxillipedal structures follow Ferrari and Ivanenko (2008). Therefore, by the application of serial homology, the nomenclature of Huys and Boxshall (1991) for Mx2 (Fig. 1.5.5, p. 26) is modified as follows: praecoxa of Mx2 is hereafter recognized as syncoxa (praecoxa and coxa), coxa is considered as the basis, and the basis is recognized as the first endopodal segment with claw. Other 
Table 1 List of additional Harpacticoida species dissected for this work, and their respective sampling coordinates and expedition name

\begin{tabular}{lllll}
\hline Species & Sampling site & RV & Expedition name & Coordinates \\
\hline Anoplosomella $\mathrm{sp}$ & Pacific nodule area & L'Atlante & NODINAUT & $14^{\circ} 2.33^{\prime} \mathrm{N} / 130^{\circ} 7.67 \mathrm{~W}$ \\
Malacopsyllus $\mathrm{sp}$ & Sedlo seamount & Meteor & OASIS & $40^{\circ} 18.3^{\prime} \mathrm{N} / 26^{\circ} 50.7^{\prime} \mathrm{W}$ \\
Eurycletodes $\mathrm{sp}$ & Seine seamount & Meteor & OASIS & $33^{\circ} 48.0^{\prime} \mathrm{N} / 14^{\circ} 21.9^{\prime} \mathrm{W}$ \\
Stenocopia $\mathrm{sp}$ & Seine seamount & Meteor & OASIS & $33^{\circ} 48.0^{\prime} \mathrm{N} / 14^{\circ} 21.9^{\prime} \mathrm{W}$ \\
\hline
\end{tabular}

$R V$ research vessel

morphological terms are used according to Huys and Boxshall (1991).

The following abbreviations are used in the text: $\mathrm{A} 1=$ antennule; Ae: aesthetasc; $\mathrm{A} 2=$ antenna; benp $=$ baseoendopod; enp = endopod; enp-1 $(2,3)=$ proximal (middle, distal) segment of endopod; exp = exopod; exp-1 $(2,3)=$ proximal (middle, distal) segment of exopod; $\mathrm{Md}=$ mandible; $\mathrm{Mx} 1=$ maxillule; $\mathrm{Mx} 2=$ maxilla $; \mathrm{Mxp}=$ maxilliped; P1-P6 = first to sixth thoracopod.

The type material has been deposited in the Forschungsinstitut und Naturmuseum Senckenberg (SMF) in Frankfurt, Germany. A list with additional material used in this work is given in Table 1. These four additional species are new to science and will be described in a future work.

\section{Descriptive part}

\section{Parameiropsidae fam. $n$.}

The diagnosis of this family is based on the reconstruction of its groundpattern.

Diagnosis Copepoda: Harpacticoida. Rostrum triangular, not fused to cephalothorax, with two sensilla on the tip. Male A1 10-segmented, haplocer, aesthetasc on 5th and last segments. Female A1 8-segmented, aesthetasc on 3rd and 8th segments. A2 dorsally bent, allobasis indistinctly separated, fused on the anterior side and without abexopodal seta; exp 1-segmented with 1 distal and 1 subdistal seta; enp 1-segmented with 7 strong spines ( 2 subdistal, 5 distal) and 3 setae ( 2 posterior to the 2 subdistal spines and 1 fused to the outermost spine), outermost spine strongly modified, robust and with strong ornamentation. Labrum represented by a triangular plate, fringed by a hyaline membrane around the tip. Mouthparts well developed, forming an oral cone with labrum. Md with elongated basis and very long gnathobasis with a sharp cutting edge, 1 long and strong distal seta on the dorsal margin and with an inner row of spinules; mandibular palp formed by an unarmed basis, exp 1-segmented with 2 distal setae, enp 1segmented with 5 distal setae. Mx1 with praecoxal arthrite very elongated with 6 slender setae, 2 setae on aboral margin and 2 setae on oral margin; coxal endite with 4 slender setae; basal endite with 4 distal and 2 subdistal setae; enp is a lobe with 2 setae; exp 1-segmented with 2 setae. Mx2 syncoxa fused to the basis; proximal endite of the basis of Mx2 with a single seta; distal basal endite with 3 setae; enp-1 drawn into a strong, sclerotized claw with a strong spine inserted proximally on the oral margin; enp- 2 with 2 slender setae. Syncoxa of Mxp with 1 distal seta; basis as long as syncoxa, unarmed; enp drawn into a strong claw with a dorsal seta. Intercoxal sclerite of P1 transversely elongated; intercoxal sclerites of P2-P4 longitudinally elongated. P1-P4 with exp and enp 3-segmented; basis, enp-1 to enp-3, and exp-1 to exp-3 with strong spinules. Basis of P1 with strong spine on inner margin; exp-1 approximately of the same size as enp-1; exp-3 with 3 outer spines and 2 distal spines/setae.

Armature of $\mathrm{P} 1-\mathrm{P} 4$ is as follows:

\begin{tabular}{lll}
\hline & Exp & Enp \\
\hline P1 & I-0; I-1; III,I1,0 & $0-1 ; 0-1 ;$ I,2,0 \\
P2 & I-1; I-1; III,I1,2 & $0-1 ; 0-1 ;$ I, 2,2 \\
P3 & I-1; I-1; III,I1,3 & $0-1 ; 0-1 ;$ I, 2,3 \\
P4 & I-1; I-1; III,I1,3 & $0-1 ; 0-1 ;$ I,2,2 \\
\hline
\end{tabular}

Male P5 medially fused; benp with outer seta on basis and 2 long spines on the endopodal lobe; exp 1-segmented, as long as wide, with 1 outer seta, 1 long distal spine and 1 shorter inner spine, with an anterior tube pore. Female P5 benp well defined, with an outer seta on basis and 3 setae on the endopodal lobe; exp 1-segmented, as long as wide, with 3 setae. Male P6 formed by 2 asymmetrical plates, each armed with 2 setae. Female P6, formed by a fused plate with 1 seta on each side. Genital double-somite with a discontinuous internal cuticular rib dorsally. Genital aperture fused; a single copulatory pore followed by a long copulatory tube; seminal receptacles paired and displaced laterally. Telson elongated, tapering distally; anal operculum not reaching the distal margin of the telson; furca with 7 setae.

Type and only genus: Parameiropsis Becker, 1974.

Type species: Parameiropsis peruanus Becker, 1974.

Other species: Parameiropsis rapiens Becker, 1974, P. magnus Itô, 1983, P. antennafortis Corgosinho and Gheerardyn, 2009, P. poseidonicus sp. n., P. neptuni sp. n., $P$. senckenbergi sp. n. and $P$. amphitriteae sp. n. 
Parameiropsis poseidonicus sp. $n$. (Figs. 1, 2, 3, 4, 5, 6, 7)

Type material Male holotype was dissected and mounted on 11 slides (Senckenberg number SMF 32043).

Type locality SE Atlantic Ocean, Angola Basin (16 $17.035^{\prime} \mathrm{S} / 5^{\circ} 27.042^{\prime} \mathrm{E} ; 5,432 \mathrm{~m}$ deep).

Etymology The name of the species refers to Poseidon, the mythic God of the sea in ancient Greek culture.

Description Habitus almost cylindrical (Fig. 1A) tapering posteriorly, with slight demarcation between prosome and urosome. Body length 1,346 $\mu \mathrm{m}$ (measured from tip of the rostrum to posterior end of the telson); cephalothorax and P2- to P5-bearing somites with weakly chitinized posterior and ventral margins; cephalothorax and second to fifth urosomites with distal hyaline membrane. Sensilla, cuticular pores and body ornamentation as in Fig. 1A, B. Telson (without furca) elongated, tapering posteriorly, about twice as long as the preceding somite (Fig. 1A, B); anal operculum (Fig. 1C) not reaching distal margin of the telson; furca tapering posteriorly, about half the length of the telson, almost 4 times longer than wide (Fig. 1A-C), with 7 setae, all inserted on the distal third; setae I, II inserted at the same level of seta VII, seta III distally to setae I and II, about the same length of the furca, longer than seta VII, seta IV2.5 times longer than telson, seta $\mathrm{V}$ longest and bipinnate, seta VI and VII of similar length. Rostrum triangular, not fused to cephalothorax, with 2 sensilla on the tip (Fig. 1A). A1 (Fig. 2A-G) 10-segmented, haplocer, armature formula as follows: $1 / 10 / 6 / 2 / 9+(1+\mathrm{Ae}) / 4 / 3 / 2 / 2 / 5+(2+\mathrm{Ae}) . \quad \mathrm{A} 2$ allobasis indistinctly separated (Fig. 3A), fused on the anterior side, without abexopodal seta; exp 1-segmented, with 1 distal and 1 subdistal seta; enp 1-segmented, with 7 strong spines ( 2 subdistal, 5 distal) and 3 setae (2 posterior to the 2 subdistal spines, and 1 distal fused to the outermost spine); outermost spine modified, piriform, with strong ornamentation and a tube pore basally. Labrum (Fig. 3B) triangular, trilobed, with a hyaline membrane around apex; outer lobe of the hyaline membrane with several long setules inserted around its distal half, and with proximal row of small spinules; sagital lobe with distal row of small spinules. Mouthparts well developed, forming an oral cone with labrum and labium. Md (Fig. 3C, D) with elongated basis, with row of spinules on the aboral margin; very long gnathobasis with a sharp cutting edge composed by 3 strong distal spines and a shorter spine between aboral and medial spines, medial and oral spines with a bifid tip; 1 long and strong seta distally inserted on the oral margin, with an inner row of spinules; basis of mandibular palp unarmed, with 3 inner setules; exp 1-segmented with 2 distal setae (outermost bipinnate); enp 1-segmented (Fig. 3C, D) with 6 setae, four of them fused together, with inner row of spinules. Praecoxal arthrite of
Mx1 (Fig. 4B) elongated, with 6 slender setae distally, 2 setae on aboral margin, 2 setae and one spine proximally on the oral margin; coxal endite with 3 subdistal spinules and 3 slender distal setae, one of them vacuolated; basal endite with 4 distal setae (1 rattail-like seta) and 2 subdistal setae on the oral margin; enp and exp indistinctly separated and with 2 setae each. Mx2 syncoxa fused to the basis; syncoxa of Mx2 (Fig. 4A) with short inner spinules; outer margin with 2 distal rows of spinules (distalmost strongly developed), and 2 strong proximal spinules; proximal endite of basis with 1 distal basal endite with 3 setae; enp-1 drawn into strong and heavily sclerotized claw, the latter denticulate along the oral margin and with a strong proximal spine, with 3 strong anterior spinules; enp-2 1-segmented, with 2 slender setae. Syncoxa of Mxp (Fig. 4C) with 1 distal bipinnate seta, an outer row of long spinules, and a transverse row of strong spinules; basis as long as the syncoxa, unarmed, with an inner longitudinal row of spinules; enp drawn into a strong claw with a seta on the oral margin. Intercoxal sclerite of P1 transversely elongated (Fig. 5A'); intercoxal sclerite P2-P4 longitudinally elongated (P2, Fig. 5B; P4, Fig. 6B; P3 like P2 and P4); P2-P4 with a large praecoxa (as wide as coxa). P1-P4 (Figs. 5A, B; 6A, B) with 3-segmented exp and 3-segmented enp; basis, exp and enp segments with strong spinules. Inner margin of basis of P2-P4 (Figs. 5B, 6A, B) with a row of long spinules. P1 (Fig. 5A) basis with a strong, modified inner spine; exp-1 nearly as long as enp-1; armature of the exp- 3 composed by 3 outer spines and 2 distal spine/setae.

Armature of $\mathrm{P} 1-\mathrm{P} 4$ as follows:

\begin{tabular}{lll}
\hline & Exp & Enp \\
\hline P1 & I-0; I-1; III,I1,0 & $0-1 ; 0-1 ; \mathrm{I}, 2,0$ \\
P2 & I-1; I-1; III,I1,2 & $0-1 ; 0-1 ; \mathrm{I}, 2,2$ \\
P3 & I-1; I-1; III,I1,3 & $0-1 ; 0-1 ; \mathrm{I}, 2,3$ \\
P4 & I-1; I-1; III,I1,3 & $0-1 ; 0-1 ; \mathrm{I}, 2,2$ \\
\hline
\end{tabular}

Both P5 medially fused (Fig. 7A); benp with outer seta on basis and 2 long spines on the endopodal lobe; exp 1segmented, as long as wide, with 1 outer seta, 1 long distal spine and 1 inner shorter spine; with an anterior tube pore. P6 (Fig. 7B) formed by 2 asymmetrical plates, each armed with 2 setae.

Parameiropsis neptuni sp. n. (Figs. 8, 9, 10, 11, 12, 13, 14, 15)

Type material: Male holotype was dissected and mounted on 9 slides (Senckenberg number SMF 32044).

Type locality SE Atlantic Ocean, Angola Basin (16 $17.035^{\prime} \mathrm{S} / 5^{\circ} 27.042^{\prime} \mathrm{E} ; 5,432 \mathrm{~m}$ deep).

Etymology The name of the species refers to Neptune, the equivalent of Poseidon in ancient Roman culture. 


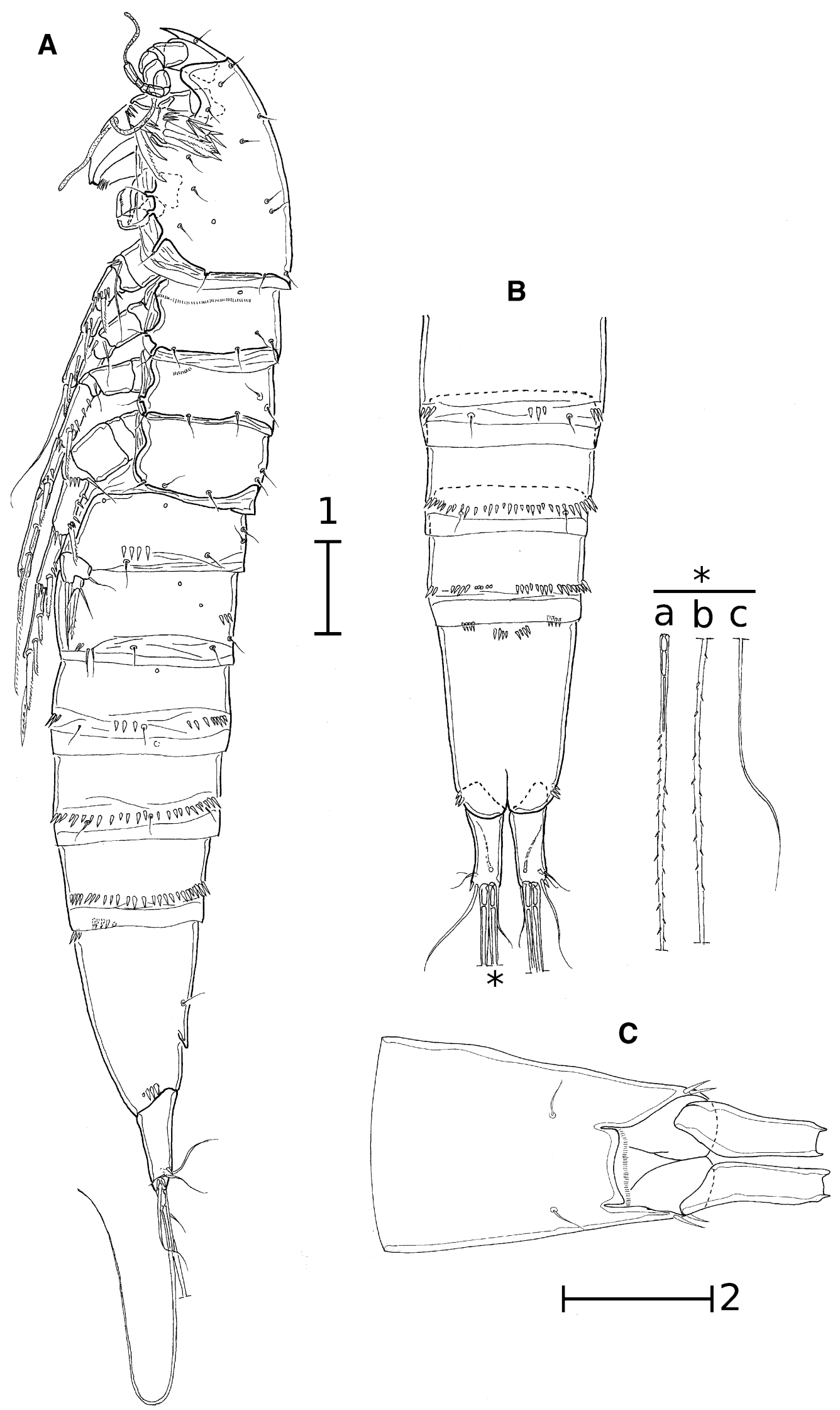

Fig. 1 Parameiropsis poseidonicus sp. n., holotype, male, SMF 32043: $A=$ lateral habitus; $B=$ ventral view of the three last urosomites, telson and furca; $C=$ dorsal view of telson; * $=$ seta $\mathrm{V} ; a, b$ and $c$ seta V showing proximal $(a)$ to distal $(c)$ partitions. Scale $1(A, B)$ and $2(C)=100 \mu \mathrm{m}$ 
Fig. 2 Parameiropsis poseidonicus sp. n., holotype, male, SMF 32043: $A=$ antennule without armature, $B-G=$ segments of antennule disarticulated, showing the arrangement of setae, spines and aesthetascs on each segment. $B=$ segments $1-3 ; C=$ segments 2-4; $D=$ segments $5-7$; $E=6-9 ; F=$ opposite view of segment $6 ; G=$ segment 9 . Scale $=50 \mu \mathrm{m}$

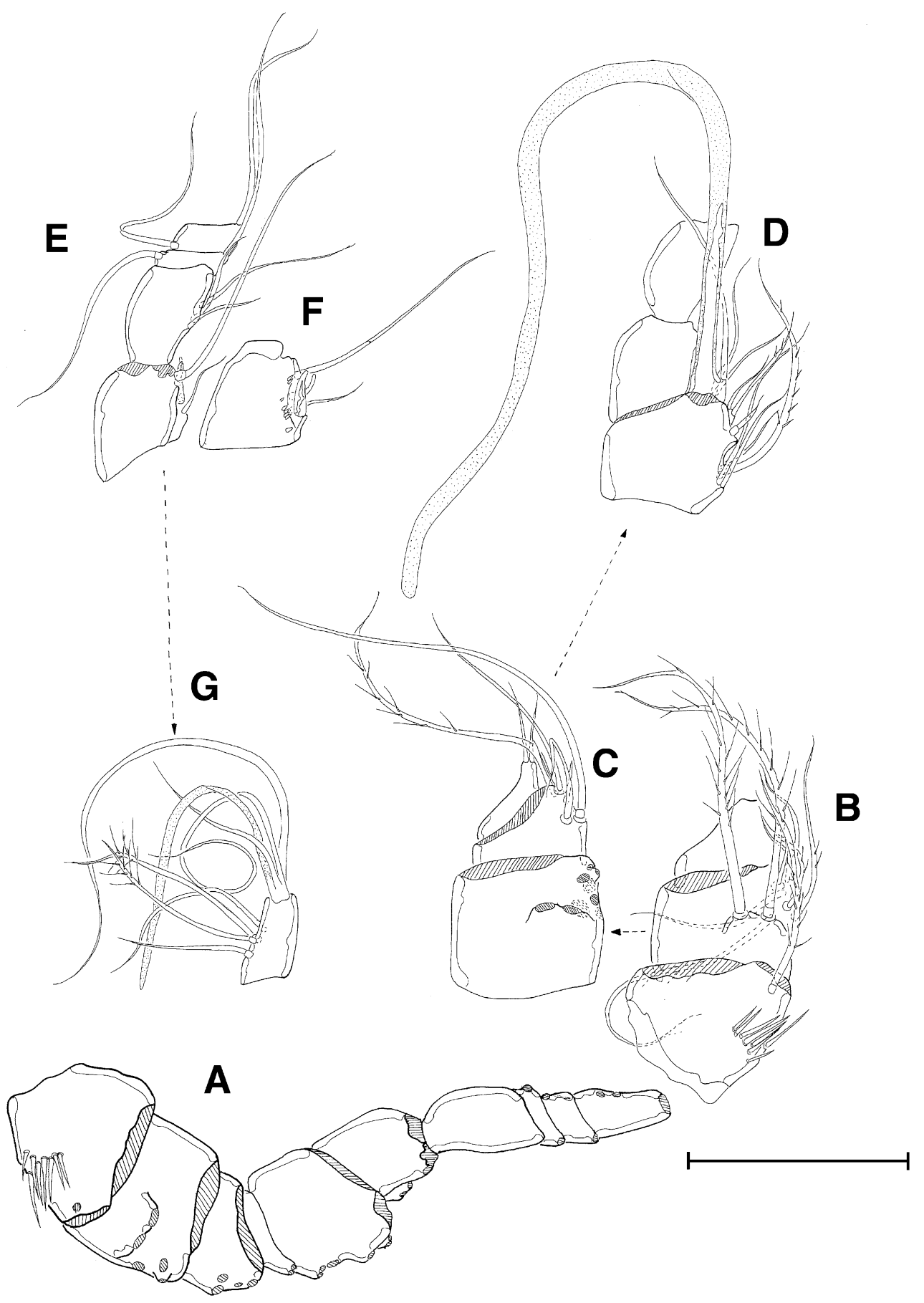

Description Habitus fusiform (Fig. 8A, B), tapering posteriorly, with slight demarcation between prosome and urosome. Body length $902 \mu \mathrm{m}$ (measured from tip of the rostrum to posterior end of the telson); cephalothorax and P2- to P5-bearing somites with weakly chitinized posterior and ventral margins; cephalothorax and second to fifth urosomites with distal hyaline membrane. Sensilla, cuticular pores and body ornamentation as in Fig. 8A, B. Telson elongated, tapering posteriorly, about twice as long as the last somite (Fig. 8A, B); anal operculum convex, not reach- ing the distal margin. Furca (Figs. 8A, B; 9A) very long, asymmetric, left ramus 12 times longer than wide, right ramus 7 times longer than wide, with 7 setae, all inserted on the distal third; setae I and II inserted at the same level of seta VII, seta III distally to setae I and II, about the same length of seta VI, longer than seta VII, seta V long, 4 times longer than telson, seta IV half the length of seta V, seta VI and VII of similar length. Rostrum triangular not fused to cephalothorax and with two sensilla on the tip. A1 (Fig. 10A-F) 9-segmented, haplocer; armature formula 1/8/ 


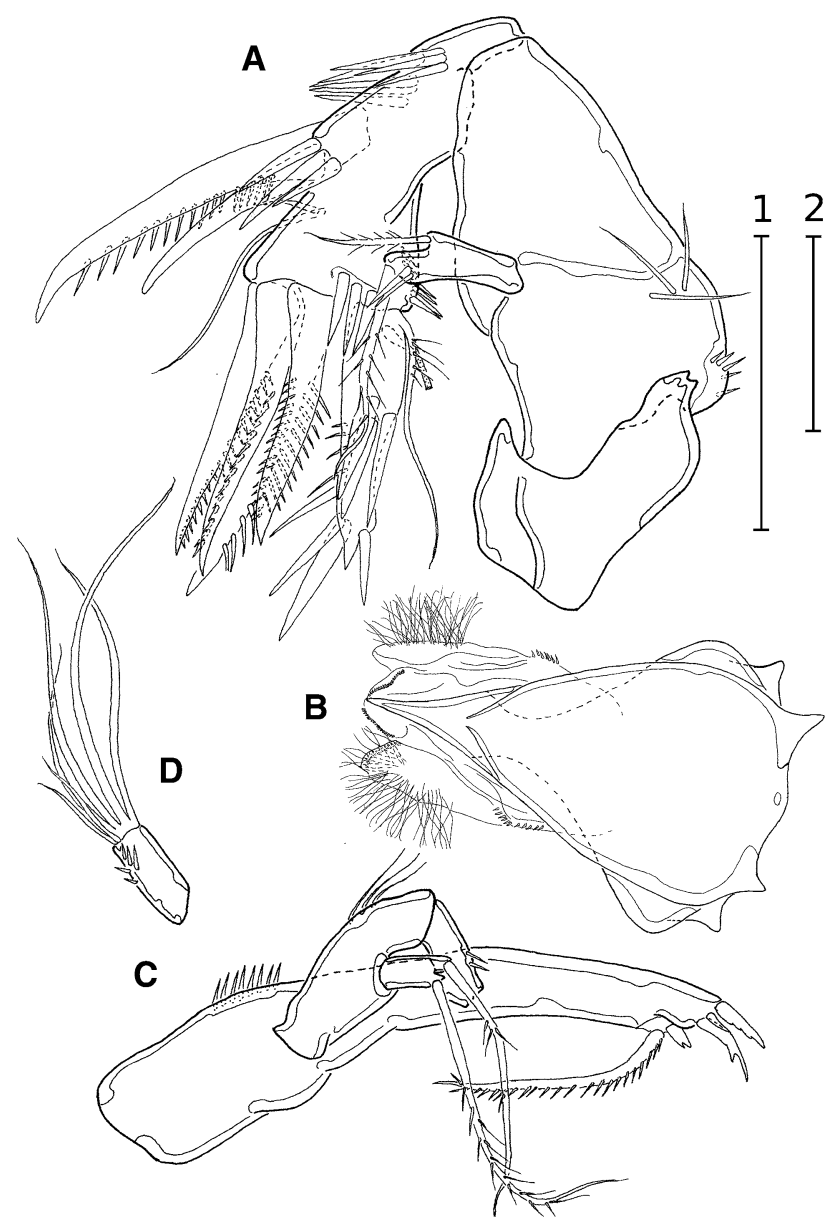

Fig. 3 Parameiropsis poseidonicus sp. n., holotype, male, SMF 32043: $A=$ antenna; $B=$ labrum; $C=$ Md and Md palp; $D=$ Md enp. Scale $1(A, C, D)$ and $2(B)=50 \mu \mathrm{m}$

$7 / 2 / 9+(1+\mathrm{Ae}) / 1 / 2 / 2 / 5+(2+\mathrm{Ae})$. A2 with indistinctly separated allobasis (Fig. 9B, C), fused on the anterior side; exp 1-segmented, with 1 distal and 1 subdistal seta; enp 1segmented, with 7 strong spines ( 2 subdistal, 5 distal) and 3 setae ( 2 posterior to the 2 subdistal spines and 1 distal seta fused to the outermost spine); outermost spine stronger than other spines, somewhat modified, with stronger ornamentation. Labrum (Fig. 11A) is a triangular plate fringed by a hyaline membrane around apex. Labium proximally bilobed, tapering distally (Fig. 11C). Mouthparts atrophied. Md (Fig. 11B) with short basis and moderately long gnathobasis with a poorly developed cutting edge; mandibular palp broken (enp lost), probably with unarmed basis like in the other congeners; exp 1-segmented, with 2 distal setae. Mx1 (Fig. 12A, A') with short praecoxal arthrite armed with 4 distal spines, 1 oral and 1 aboral seta; coxal endite with 5 slender setae; basal endite with 4 distal and 1 subdistal seta; enp represented by 2 setae; exp represented by a distinct segment with 1 long and 1 short seta. Mx2 without distinct segmentation (Fig. 12B); proximal basal endite represented by a single seta; distal basal endite weakly devel-

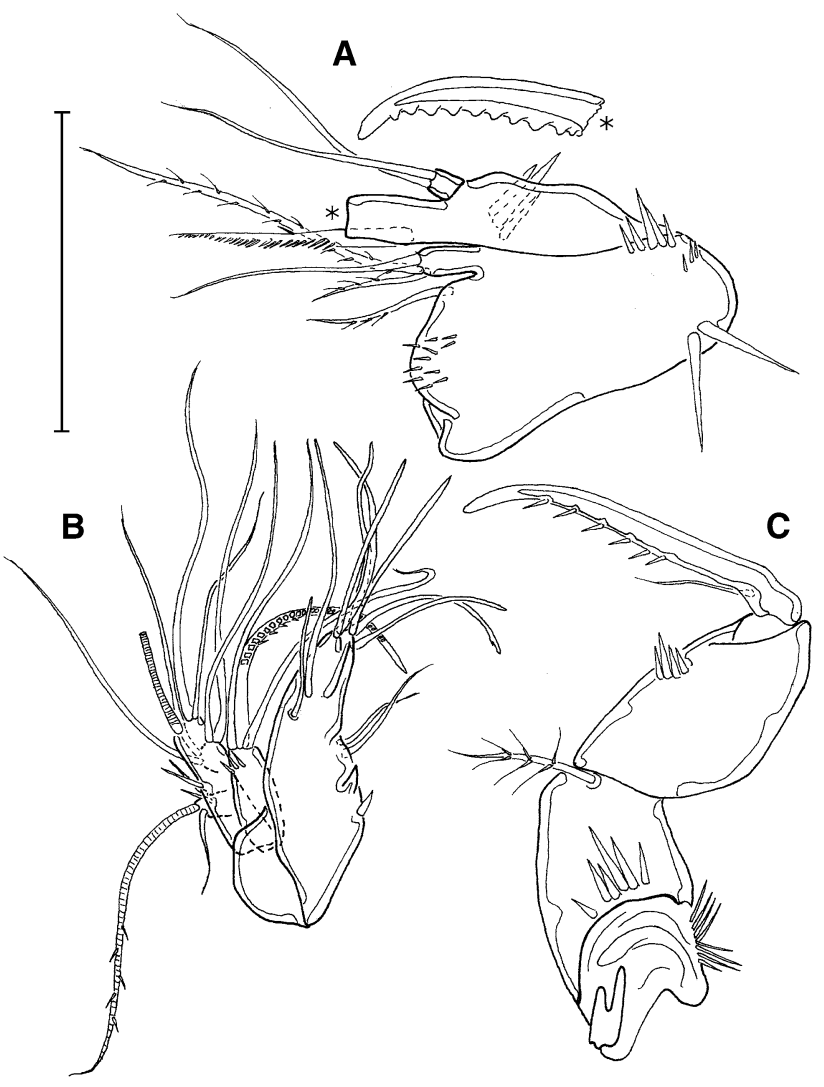

Fig. 4 Parameiropsis poseidonicus sp. n., holotype, male, SMF 32043: $A=\mathrm{Mx} 2 ; B=\mathrm{Mx} 1 ; C=\mathrm{Mxp} ;$ Asterisk indicates where the enp-1 claw is broken. Scale $=50 \mu \mathrm{m}$

oped, with 2 setae; enp-1 with an upwardly directed spiniform process; enp-2 represented by 2 setae inserted on a small lobe. Mxp (Fig. 12C) with praecoxa separated from coxa; basis unarmed, enp fused to the basis, forming an allobasis; enp armature reduced to a small, blunt spine distally (claw) and a subdistal small seta. Intercoxal sclerite of $\mathrm{P} 1$ transversely elongated; intercoxal sclerites of P2-P4 longitudinally elongated. P1-P4 (Figs. 13A, B; 14A, B) with 3-segmented exp and 3-segmented enp; basis, exp and enp segments with strong spinules, basis with inner row of long spinules. P1 (Fig. 13A) basis with strong inner spine (longer than the exp-1 and exp-2 combined) and with spinules along its outer margin; exp-1 nearly as long as enp-1; exp- 3 with 3 outer spines and 2 distal setae.

Armature of P1-P4 as follows:

\begin{tabular}{lll}
\hline & Exp & Enp \\
\hline P1 & I-0; I-1; III,2,0 & $0-1 ; 0-1 ; \mathrm{I}, 2,0$ \\
P2 & I-1; I-1; III,I1,2 & $0-1 ; 0-1 ; \mathrm{I}, 2,2$ \\
P3 & I-1; I-1; III,I1,3 & $0-1 ; 0-1 ; \mathrm{I}, 2,3$ \\
P4 & I-1; I-1; III,I1,3 & $0-1 ; 0-1 ; \mathrm{I}, 2,2$ \\
\hline
\end{tabular}


Fig. 5 Parameiropsis poseidonicus sp. n., holotype, male, SMF 32043: $A=\mathrm{P} 1$

$\left(A^{\prime}=\right.$ intercoxal sclerite, praecoxa, coxa and basis of P1);

$B=\mathrm{P} 2\left(B^{\prime}=\right.$ exp-3;

$B^{\prime \prime}=$ intercoxal sclerite, coxa and basis of P2). Asterisk indicates a broken seta.

Scale $=50 \mu \mathrm{m}$

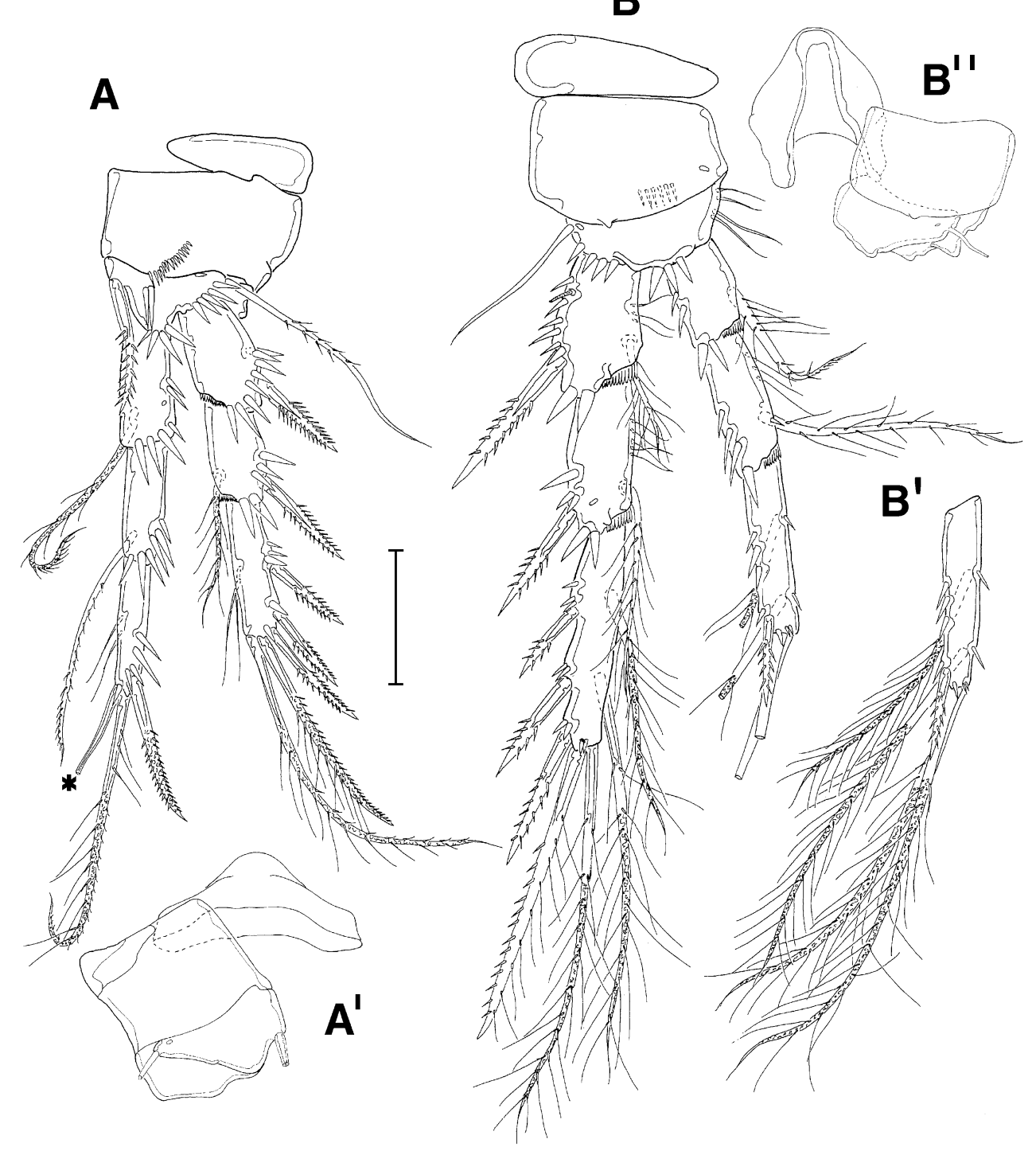

B
P5 (Fig. 15A) represented by a fused plate; benp and exp fused, with 1 outer seta on the basis, endopodal lobe with 2 strong distal spines and 1 inner seta; exp fused to benp, with 1 outer seta and 2 strong distal spines (outermost longer). P6 (Fig. 15B) formed by 2 asymmetrical plates, each armed with 1 outer seta and 1 strong distal spine.

Parameiropsis senckenbergi sp. n. (Figs. 16, 17, 18, 19, 20, $21,22,23)$

Type material Male holotype was dissected and mounted on 8 slides (Senckenberg number SMF 32045).

Type locality Guinea Basin $\left(0^{\circ} 50.0^{\prime} \mathrm{N} / 5^{\circ} 35.0^{\prime} \mathrm{W} ; 5,138 \mathrm{~m}\right.$ deep).

Etymology This species is dedicated to Dr. Johann Christian Senckenberg in commemoration of the 300th anniversary of his birthday.
Description Body almost cylindrical (Fig. 16A, B), tapering posteriorly, with slight demarcation between prosome and urosome. Body length, 1,007 $\mu \mathrm{m}$ (measured from the tip of the rostrum to posterior end of the telson); cephalothorax and somites bearing P2-P5 fringed with a slightly chitinized margin; cephalothorax and urosomites $2-5$ with distal hyaline membrane. For sensilla, cuticular pores and body ornamentation see Fig. 16A, B. Telson elongated, tapering posteriorly, about twice as long as the preceding somite (Figs. 16A, B; 17A); anal operculum concave, not reaching the distal margin of the telson. Furca symmetrical (Figs. 16A, B; 17A), at about 6 times longer than wide, with 7 setae, all inserted on the distal third; setae I and II inserted at the same level of seta VII; seta III distally to setae I and II, shorter than furca, longer than seta VI and VII; seta IV long, 1.8 times longer than telson; seta $\mathrm{V}$ longest and bipinnate, twice as long as seta IV. Rostrum triangular, 
Fig. 6 Parameiropsis poseidonicus sp. n., holotype, male, SMF 32043: $A=\mathrm{P} 3 ; B=\mathrm{P} 4$. Scale $=50 \mu \mathrm{m}$

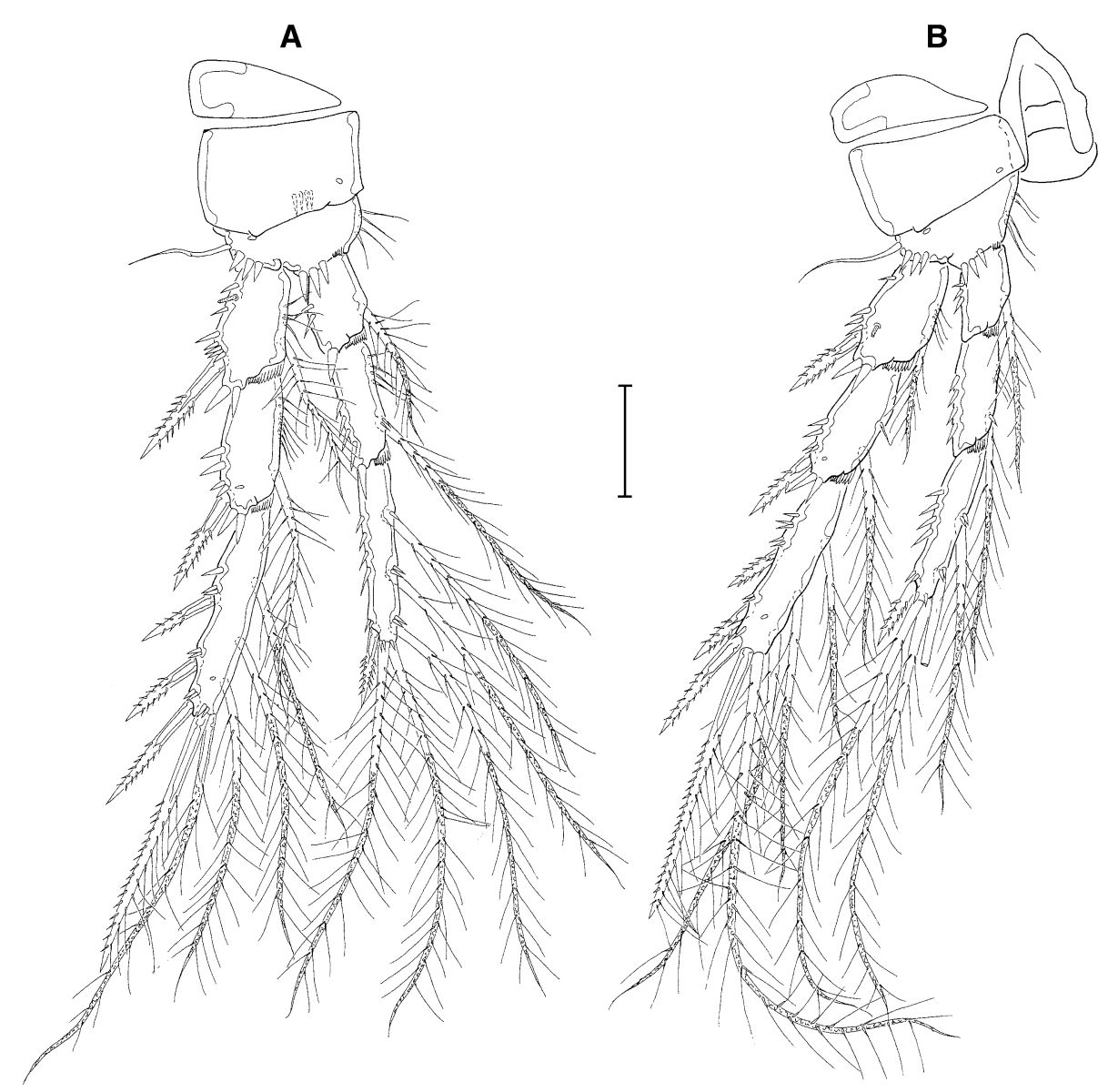

not fused to cephalothorax, with two sensilla on the tip (Fig. 18A). A1 (Fig. 18A-F) 9-segmented, haplocer, armature formula $1 / 9 / 5 / 2 / 9+(1+\mathrm{Ae}) / 1 / 2 / 2 / 5+(2+\mathrm{Ae})$. A2 with indistinctly separated allobasis (Fig. 19A), fused on the anterior side; exp 1-segmented, with 1 distal and 1 subdistal seta; enp 1-segmented, with 7 strong spines ( 2 subdistal, 5 distal) and 3 setae ( 2 posterior to the 2 subdistal spines and 1 distal seta fused to the outermost spine); outermost spine stronger than the others, somewhat modified, with stronger ornamentation. The labrum is a triangular plate fringed by a hyaline membrane around apex. Labium trilobed distally (Fig. 17B). Mouthparts atrophied. Md (Fig. 19B) with short basis and gnathobasis, with a poorly developed cutting edge; mandibular palp well developed; exp well developed, fused to the basis, with 2 distal pinnate setae; enp 1-segmented, with 4 setae, 2 of which fused to the segment; basis unarmed. Mx1 (Fig. 20A) with short praecoxal arthrite, the latter with 7 rudimentary spines; coxal endite with 4 very short setae; basal endite with 5 distal setae; enp represented by 2 setae; exp represented by a segment (fused to basis) with 1 long and 1 short seta. Mx2 without distinct segmentation (Fig. 20B); syncoxa

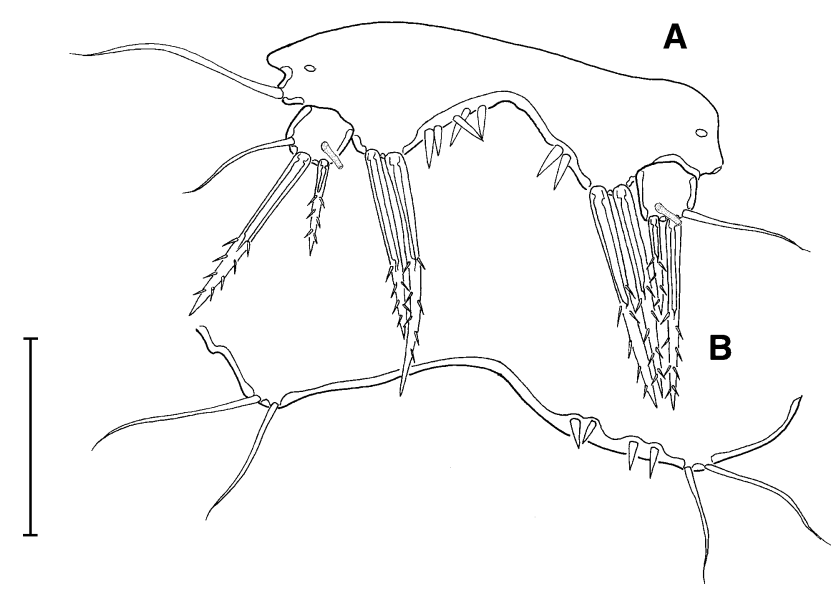

Fig. 7 Parameiropsis poseidonicus sp. n., holotype, male, SMF 32043: $A=\mathrm{P} 5 ; B=\mathrm{P} 6$. Scale $=50 \mu \mathrm{m}$

and basis unarmed; enp-1 with an upward directed spiniform process, with an accessory seta; enp- 2 represented by 2 setae. Mxp (Fig. 20C) with syncoxa separated from the basis; enp fused to the basis forming an allobasis, allobasis bare; enp armature reduced to a small, blunt 


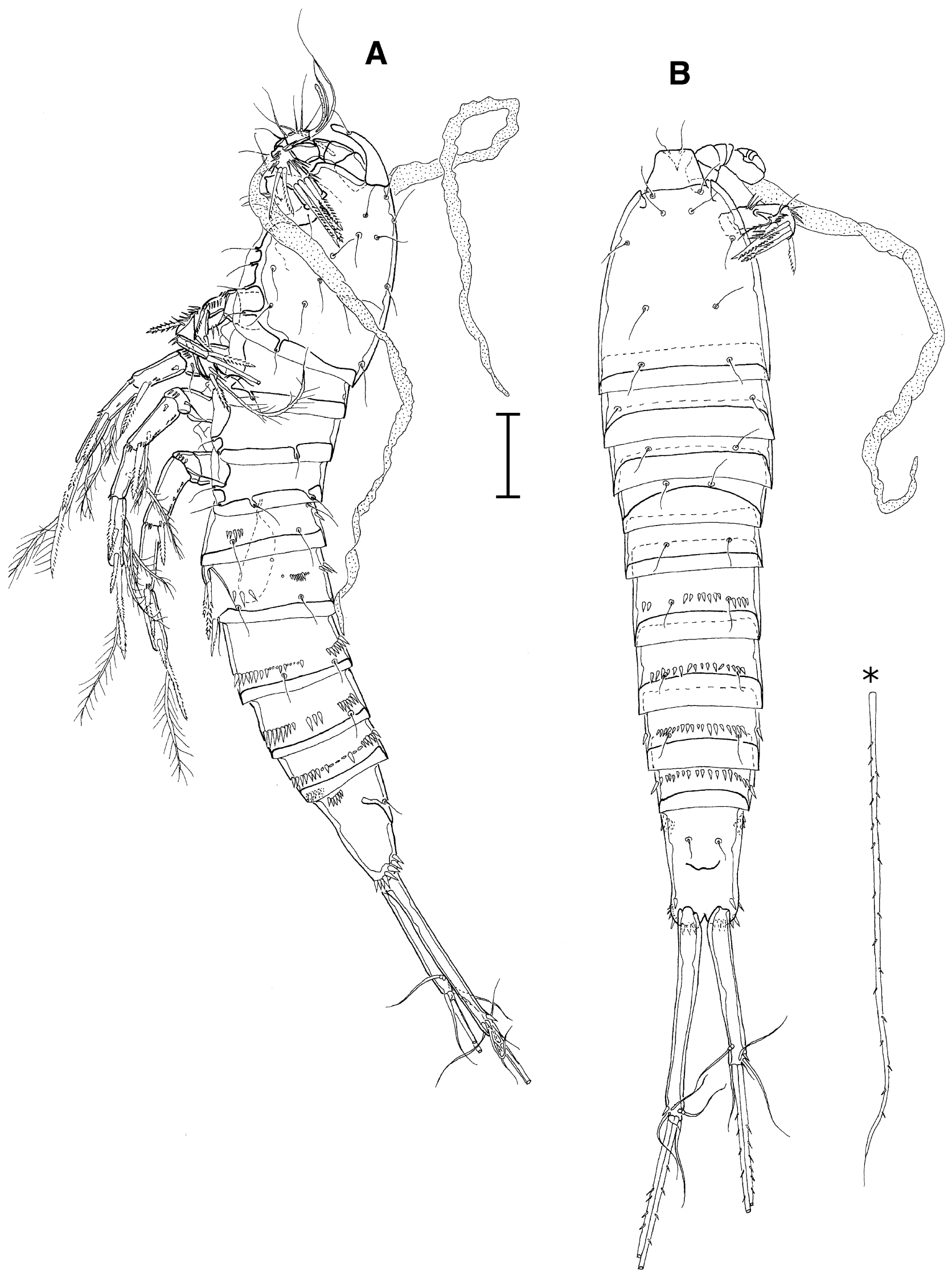

Fig. 8 Parameiropsis neptuni sp. n., holotype, male, SMF 32044: $A=$ lateral habitus; $B=$ dorsal habitus; $*$ full length of seta V. Scale $=100 \mu \mathrm{m}$ 
Fig. 9 Parameiropsis neptuni sp. n., holotype, male, SMF 32044: $A=$ dorsal view of telson and furca; $B, C=$ antenna. Scale $=100 \mu \mathrm{m}$

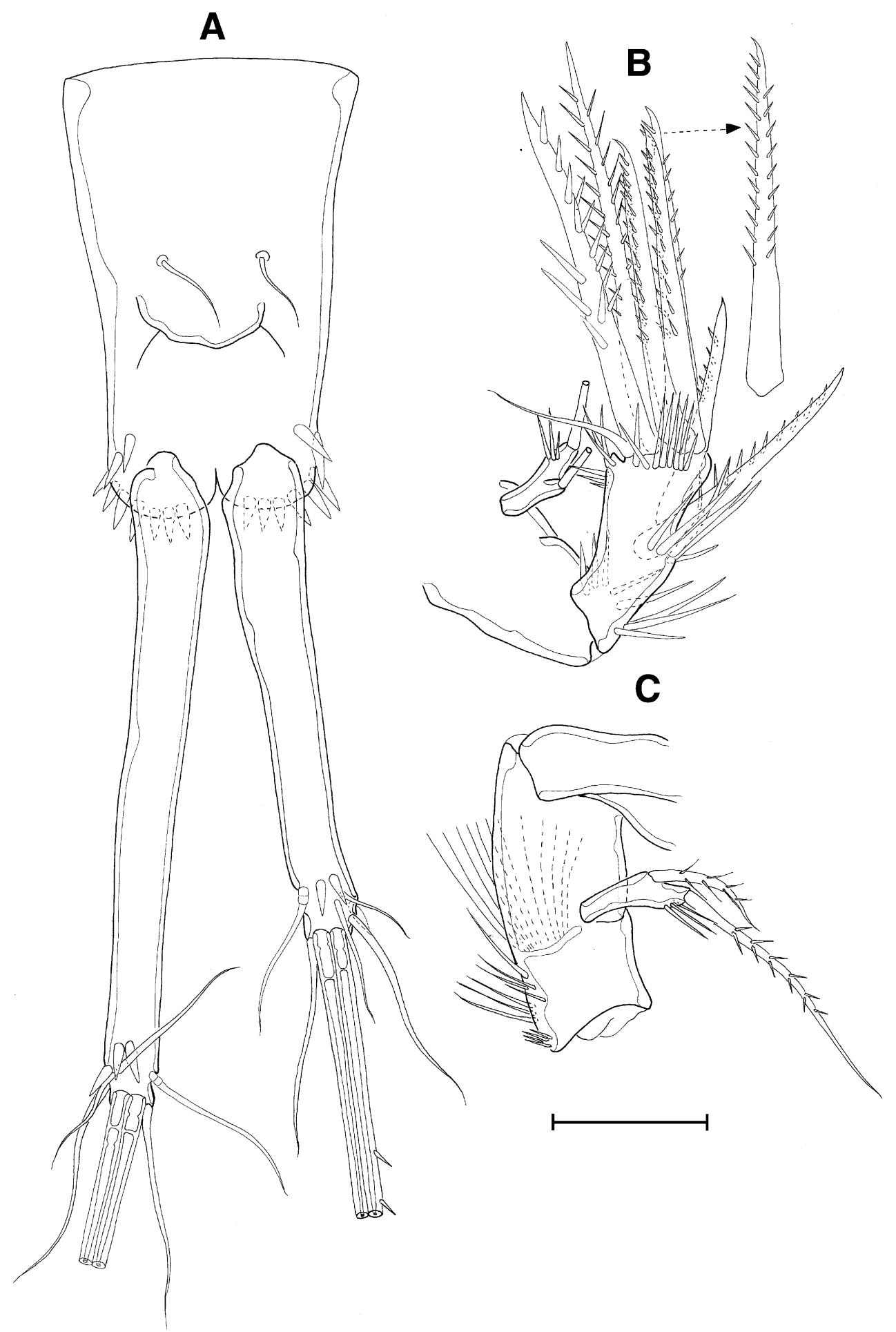

spine distally (claw). P1 intercoxal sclerite transversely elongated; intercoxal sclerites of P2-P4 longitudinally elongated. P1-P4 (Figs. 21A, B; 22A, B) with 3-segmented exp and enp; exp and enp segments with strong spinules; basis with inner row of long spinules. Basis of P1 (Fig. 21A) with a very strong inner spine (longer than exp-1); exp-1 nearly as long as enp-1; exp-3 with 3 outer spines and 2 distal setae. 
Fig. 10 Parameiropsis neptuni sp. n., holotype, male, SMF 32044: $A$ = antennule without armature in a geniculate view, $B-G=$ segments of antennule disarticulated, showing the arrangement of setae, spines and aesthetascs on each segment. $B=$ segments $1-4 ; C=$ segment 5; $D=$ segment 5 in opposite view; $E=$ segment 6 ; $F=$ segments $7-8$ and $G=$ segment 9 . Scale $=50 \mu \mathrm{m}$

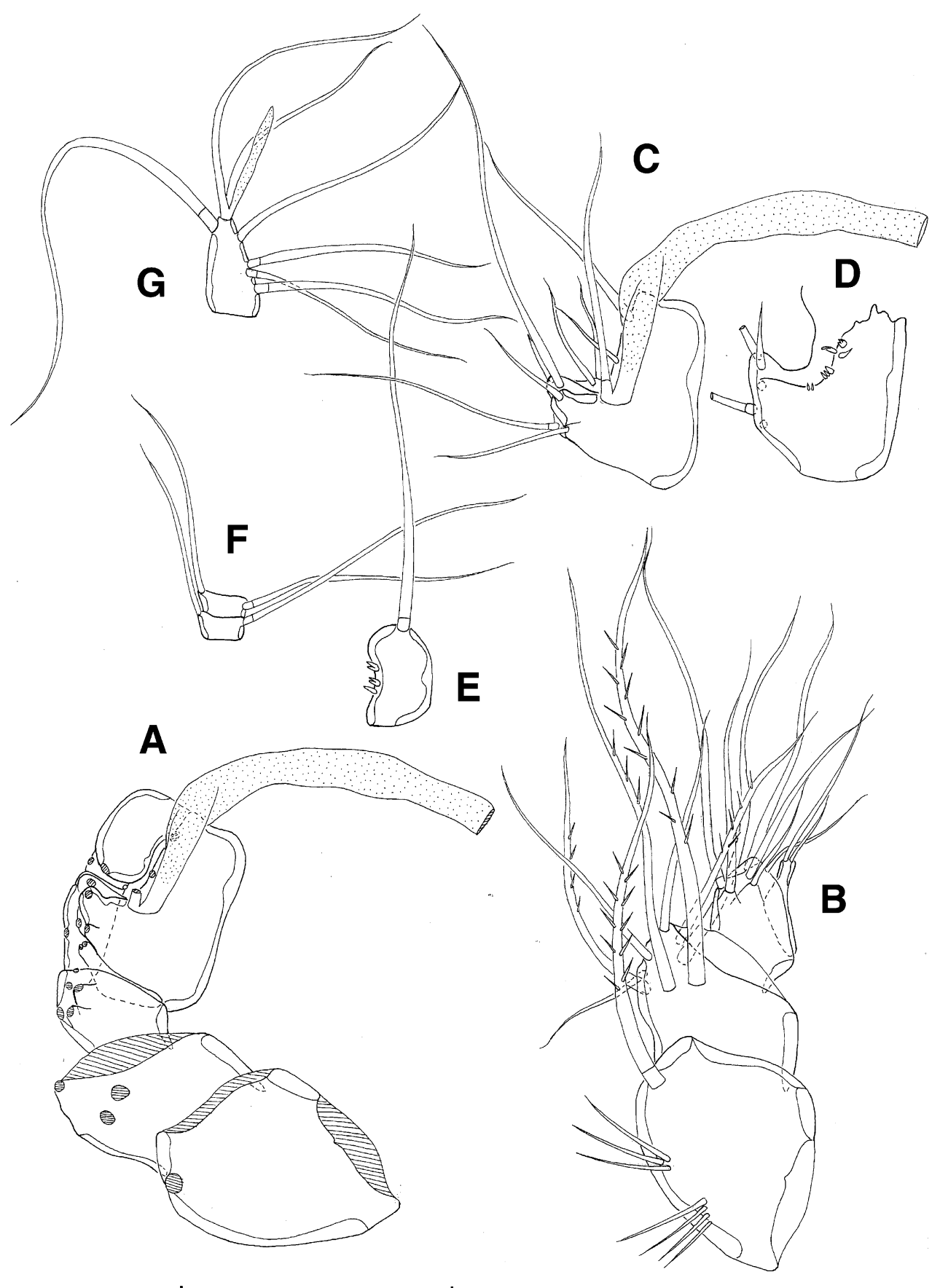

Armature of P1-P4 as follows:

\begin{tabular}{lll}
\hline & Exp & Enp \\
\hline P1 & I-0; I-1; III,2,0 & $0-1 ; 0-1 ;$ I,2,0 \\
P2 & I-1; I-1; III,I1,2 & $0-1 ; 0-1 ;$ I,2,2 \\
P3 & I-1; I-1; III,I1,3 & $0-1 ; 0-1 ;$ I,2,3 \\
P4 & I-1; I-1; III,I1,3 & $0-1 ; 0-1 ;$ I,2,2 \\
\hline
\end{tabular}

P5 (Fig. 23) represented by a fused plate; benp with outer seta on the basis, endopodal lobe with 2 strong distal spines; exp slightly longer than wide, with an outer seta and 2 strong distal spines (outermost is bigger). P6 (Fig. 23) represented by 2 asymmetrical plates, each with an outer seta and a strong distal spine.

Parameiropsis amphitriteae sp. n. (Figs. 24, 25, 26, 27, 28, 29)

Type material Female holotype was dissected and mounted on 4 slides (Senckenberg number SMF 32046). 


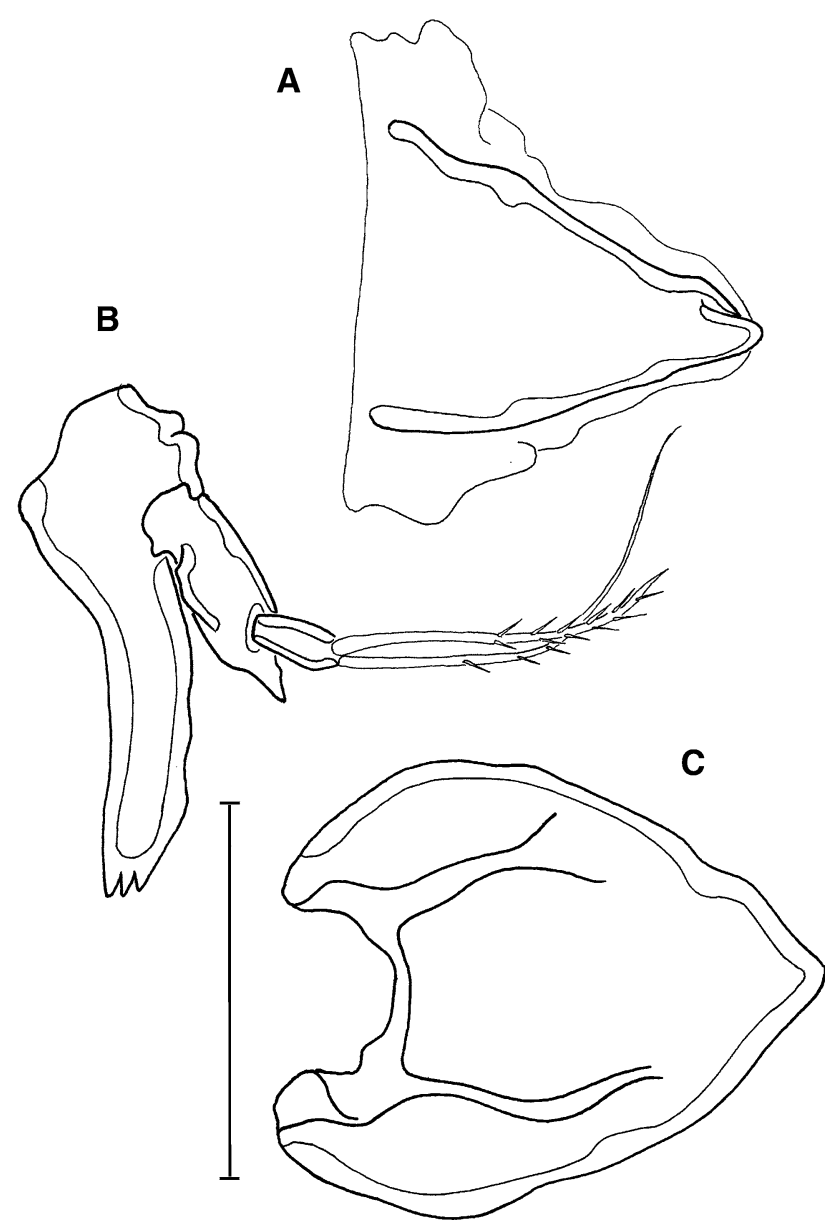

Fig. 11 Parameiropsis neptuni sp. n., holotype, male, SMF 32044: $A=$ labrum, $B=\mathrm{Md}$ and Md palp (Md palp is broken lacking the enp), $C=$ labium. Scale $=50 \mu \mathrm{m}$

Type locality Laptev see $\left(78^{\circ} 01.9^{\prime} \mathrm{N} / 102^{\circ} 17.5^{\prime} \mathrm{E} ; 1,100 \mathrm{~m}\right.$ deep).

Etymology The name of the species refers to Amphitrite, a Nereid, wife of Poseidon in the ancient Greek mythology.

Description Body almost cylindrical (Fig. 24A, B), tapering posteriorly, with slight demarcation between prosome and urosome. Body length, $910 \mu \mathrm{m}$ (measured from the tip of the rostrum to posterior end of the telson); cephalothorax and somites bearing P2-P5 fringed with a poorly chitinized margin; cephalothorax and urosomites $2-5$ with distal hyaline membrane; double genital-somite with a discontinuous internal cuticular rib dorso-laterally. For sensilla, cuticular pores and body ornamentation see Fig. 24A, B. Telson elongated, about twice as long as the preceding somite (Fig. 24A, B); anal operculum not reaching the distal margin of the telson. Furca (Figs. 24A, B; 27) 3 times longer than wide, with 6 setae, all inserted on the distal third; setae I absent, II inserted distally to seta III, seta III strong (broken), seta IV slightly longer than furca, seta $\mathrm{V}$ well devel-

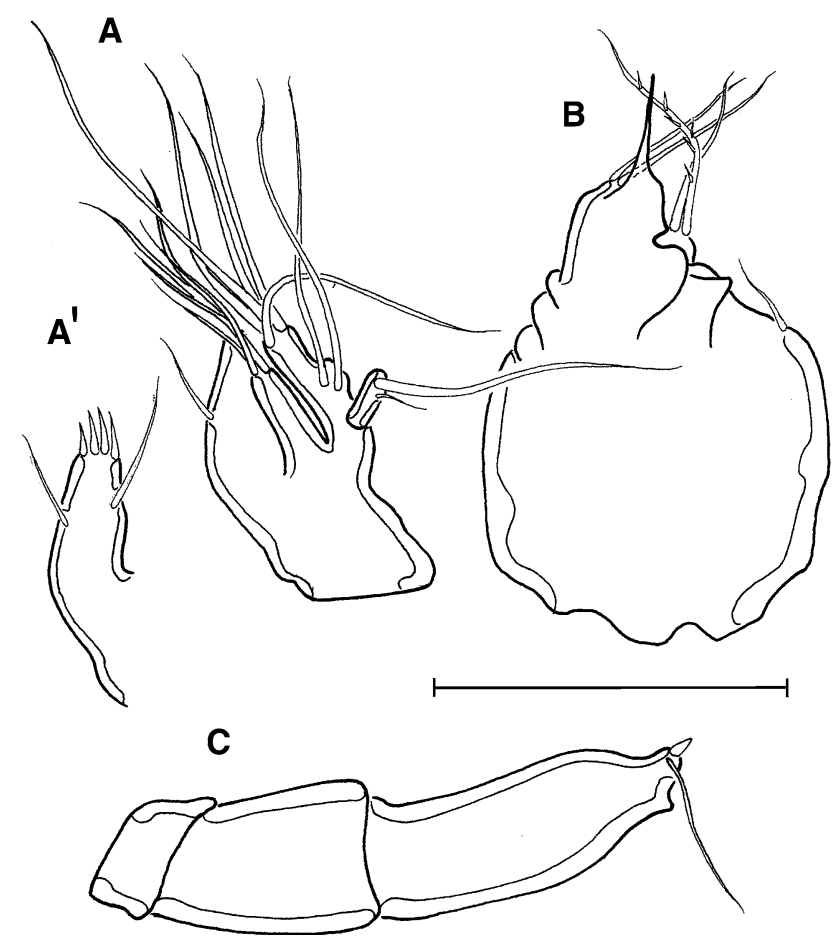

Fig. 12 Parameiropsis neptuni sp. n., holotype, male, SMF 32044: $A=\operatorname{Mx} 1\left(A^{\prime}=\right.$ praecoxal arthrite $), B=\operatorname{Mx} 2, C=$ Mxp. Scale $=50 \mu \mathrm{m}$

oped (broken), seta VI shorter than furca, seta VII broken; inner margin with a longitudinal row of spinules. Rostrum triangular, not fused to cephalothorax, with 2 sensilla on the tip. A1 (Fig. 29A) 8-segmented; armature formula 1/6/ $4+$ Ae/0/1/1/2/6 + Ae. A2 with indistinctly separated allobasis (Fig. 25A), fused on the posterior side; exp 1-segmented, with 1 distal spine and 1 subdistal seta; enp 1-segmented, with 7 strong spines ( 2 subdistal, 5 distal) and 1 distal seta fused to the outermost spine; outermost spine modified, somewhat inflated, with strong ornamentation. Labrum (Fig. 25C) is a triangular plate fringed by a hyaline membrane around apex. Mouthparts well developed, forming an oral cone with labrum and labium. Md (Fig. 25B, B') with elongated basis, with a very long gnathobasis, and a welldeveloped cutting edge; mandibular palp formed by an unarmed basis; enp 1-segmented, with 5 distal setae and a row of distal spinules; exp represented by 2 setae inserted on a small lobe. Mx1 (Fig. 26A, A') with very elongated praecoxal arthrite, the latter with 6 slender setae, 2 distal setae, 2 setae and 1 spine on the dorsal margin; coxal endite with 3 slender setae; basal endite with 2 bare setae, 1 bipinnate seta and 2 subdistal setae; enp represented by a lobe with 2 setae; exp represented by an indistinct segment with 1 seta. Mx2 syncoxa fused to the basis; syncoxa of $M x 2$ (Fig. 26B) with a proximal transverse row of strong spinules; proximal basal endite represented by a single seta; distal basal endite with 3 setae; enp-1 drawn into a strong, 
Fig. 13 Parameiropsis neptuni sp. n., holotype, male, SMF 32044: $A=\mathrm{P} 1 ; B=\mathrm{P} 2$.

Scale $=50 \mu \mathrm{m}$

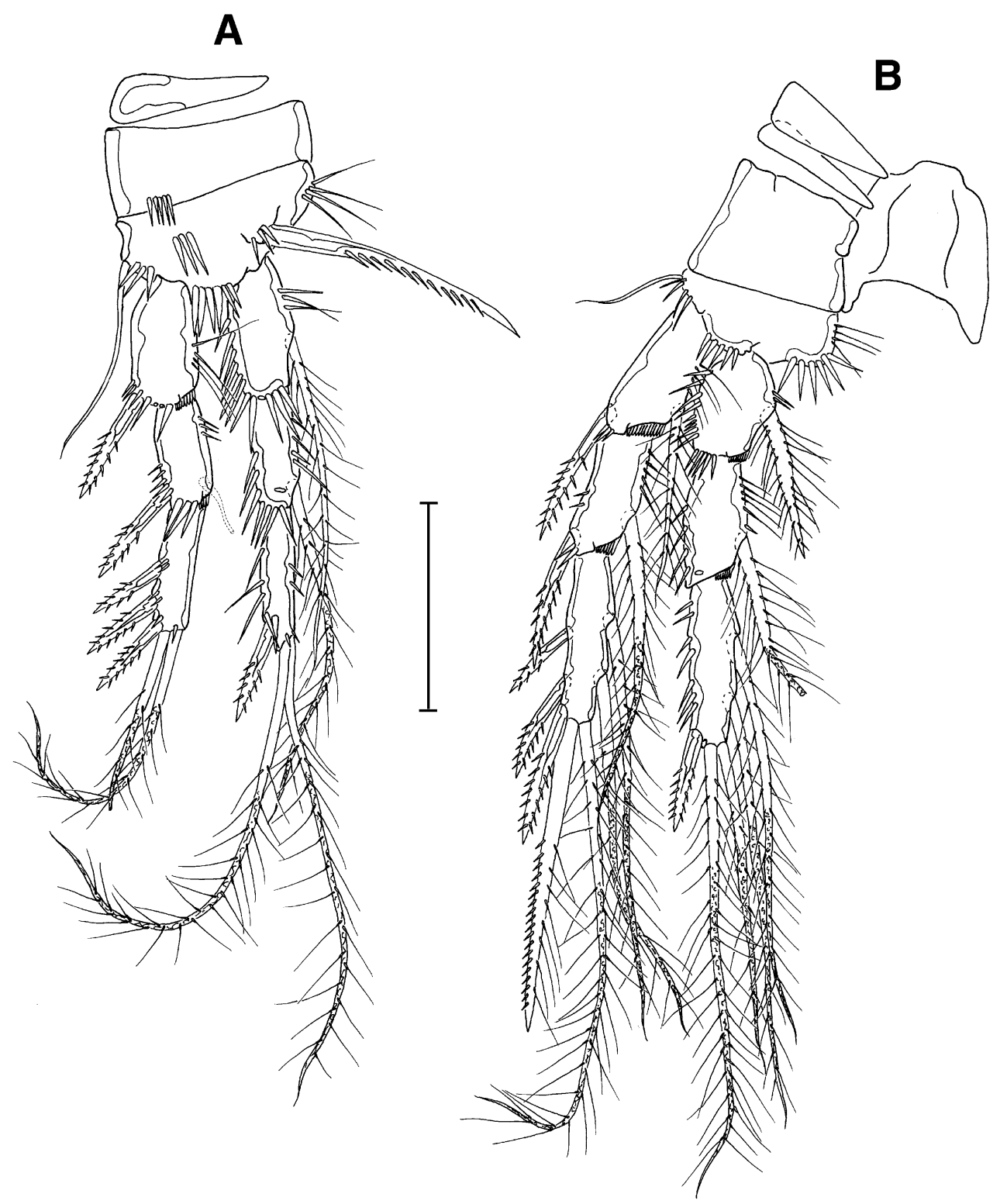

very sclerotized claw, the latter denticulated along the dorsal margin and with a strong spine on its proximal dorsal edge; enp-2 represented by 2 slender setae. Syncoxa of Mxp (Fig. 26C) with distal seta probably broken (a short lobe with an insertion pit can be seen on the inner margin) and a proximal transverse row of strong spinules; basis bare, with a transverse row of spinules on the distal third; enp formed by a strong claw, strongly ornamented and with a dorsal seta. P1 intercoxal sclerite transversely elongated; intercoxal sclerites of P2-P4 longitudinally elongated. P1P4 (Figs. 27A, B; 28A, B) with 3-segmented exp and enp; distal margin of basis with strong spinules. Exp and enp of P2-P4 (Figs. 27B; 28A, B) slightly ornamented; with a short seta on the inner margin of exp and enp segments of P2-P4. Basis of P1 (Fig. 27A) with a strong inner spine, not reaching the distal margin of the enp-1, a row of strong outer spinules and 2 inner spinules; exp- 1 shorter than the enp-1; exp-3 with 2 outer spines, 1 distal spine and 1 distal seta.

Armature of $\mathrm{P} 1-\mathrm{P} 4$ is as follows:

\begin{tabular}{lll}
\hline & Exp & Enp \\
\hline P1 & I-0; I-1; II,I1,0 & $0-1 ; 0-1 ;$ I,I,1 \\
P2 & I-0; I-1; II,I1,2 & $0-I ; 0-1 ;$ I, 2,2 \\
P3 & I-0; I-1; II,2,3 & $0-I ; 0-1 ;$ I, 2,2 \\
P4 & I-0; I-1; II,2,I1 & $0-I ; 0-1 ;$ I,2,2 \\
\hline
\end{tabular}

P5 (Fig. 27D) represented by a fused plate; benp weakly developed, with an outer basal seta and with 2 long spines on endopodal lobe, 2 setae, 1 spine and 1 tube pore on the outer exopodal lobe. P6 (29B) formed by a fused plate with 
Fig. 14 Parameiropsis neptuni sp. n., holotype, male, SMF 32044: $A=\mathrm{P} 3\left(A^{\prime}=\exp -3\right)$; $B=\mathrm{P} 4$. Scale $=50 \mu \mathrm{m}$

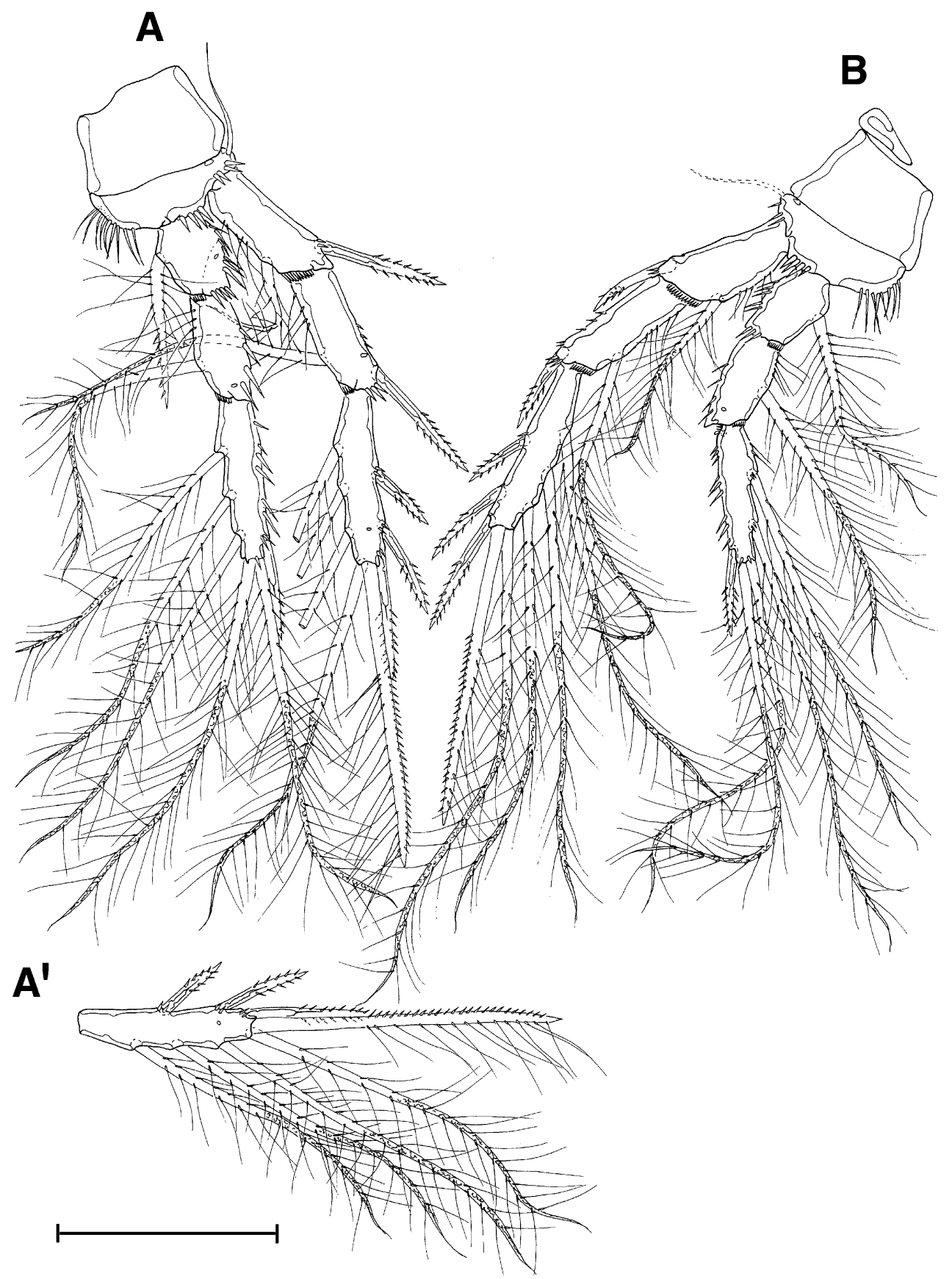

African deep-sea site and $P$. peruanus from the deep sea in the Peru basin. Later, Itô (1983) described the female of $P$. magnus from a deep-sea site next to Mindanao Island, Philippines, in the Pacific Ocean. Recently, Corgosinho and Gheerardyn (2009) described a female of $P$. antennafortis from Porcupine Seabight (NE Atlantic Ocean).

The analysis of the phylogeny of the species within Parameiropsis lies beyond the scope of this paper. However, it is interesting to notice that, in spite of their geographical proximity (both from the Angola Basin), P. poseidonicus sp. n. and P. neptuni sp. n. do not appear to be so closely related, as evidenced by the different number group the species Parameiropsis rapiens from a Northern 


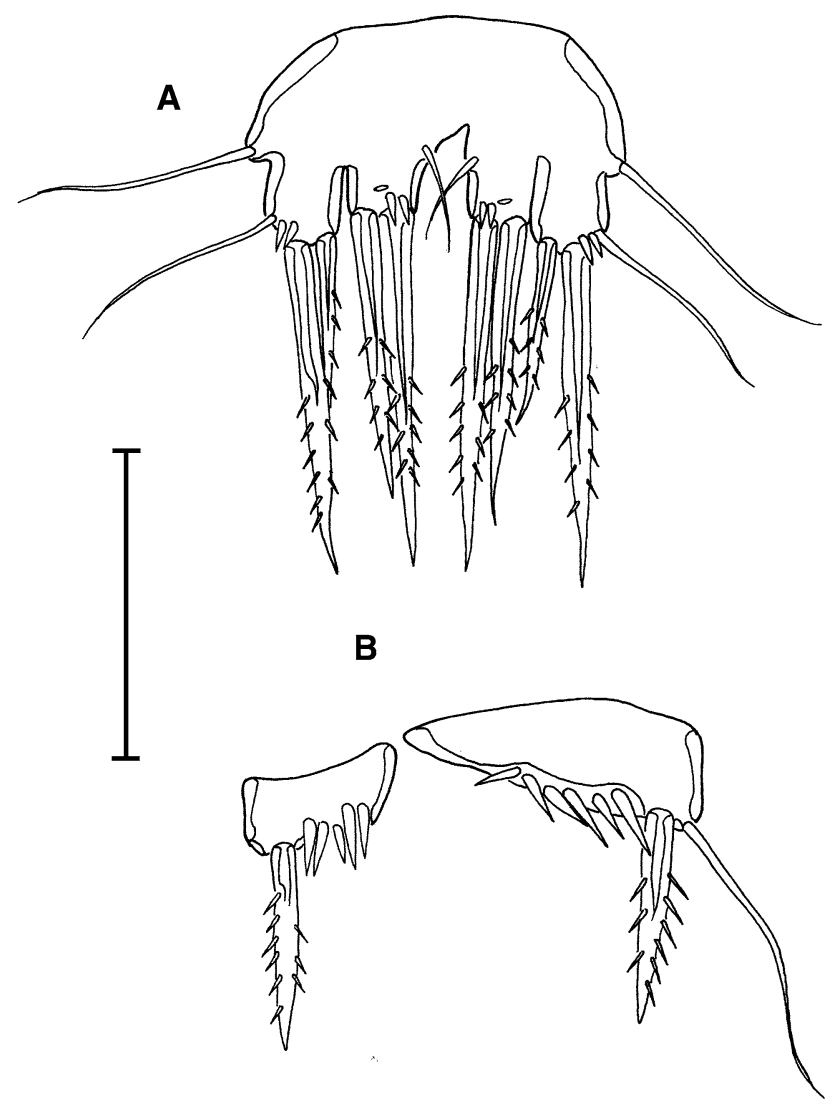

Fig. 15 Parameiropsis neptuni sp. n., holotype, male, SMF 32044: $A=\mathrm{P} 5 ; B=\mathrm{P} 6$. Scale $=50 \mu \mathrm{m}$

of A1 segments ( 5 and 4 segments distally from the proximal aesthetasc-bearing-segment in $P$. poseidonicus sp. $\mathrm{n}$. and $P$. neptuni sp. n., respectively), relative length of the proximal aesthetasc of A1 (much larger in P. neptuni sp. $\mathrm{n}$.), robustness of the outermost seta on the A2 enp (more robust and heavily ornamented in P. poseidonicus sp. n., less robust and less transformed in P. neptuni sp. n.), degree of development of the mouthparts (atrophied in P. neptuni sp. n.), length of the inner spine on the basis of P1 (comparatively larger in P. neptuni sp. n.), shape and length of the furca (short and symmetrical in $P$. poseidonicus sp. n., long and asymmetrical in P. neptuni sp. n.), segmentation of P5 (exp fused to benp in $P$. neptuni sp. n.) and body length ( $P$. poseidonicus sp. $\mathrm{n}$. is larger than $P$. neptuni $\mathrm{sp} . \mathrm{n}$ ).

Parameiropsis neptuni sp. n. seems to be closely related to $P$. senckenbergi $\mathrm{sp}$. $\mathrm{n}$. as shown by the presence of a large proximal aesthetasc on the A1 in both species, the number and homology of A1 segments and the atrophy of the mouthparts. They also share the presence of an outer, flexible and bipinnate seta (with inner and outer setules) on the distal margin of exp-3 of P1 (present as a spine with outer spinules and inner setules in $P$. poseidonicus sp. n., $P$. magnus, $P$. rapiens, $P$. peruanus and $P$. antennafortis; in $P$. amphitriteae sp. $\mathrm{n}$., this spine is transformed into a short and strong bipinate spine). According to Corgosinho and Gheerardyn (2009), the presence of an outer, flexible and bipinnate seta on the distal margin of exp-3 of P2-P4 is apomorphic, instead of a spine, with outer spinules and inner setules. The same argument can be used to support a hypothesis that the presence of an outer, flexible and bipinnate seta on the distal margin of exp- 3 of $\mathrm{P} 1$ is apomorphic for $P$. neptuni sp. n. and P. senckenbergi sp. n. Giving the low number of described species, it is still difficult to propose a phylogenetic scheme within Parameiropsis. For example, we cannot, at this moment, define any synapomorphy for a putative monophyletic group that we consider is formed by $P$. poseidonicus sp. n., P. magnus, P. rapiens, $P$. peruanus, $P$. antennafortis and $P$. amphitriteae sp. $\mathrm{n}$. On the contrary, $P$. neptuni sp. n. and P. senckenbergi sp. n. share some characters that we consider synapomorphic.

Parameiropsis amphitriteae sp. $\mathrm{n}$. and P. antennafortis are considered the most derived species within the genus as evidenced by the reduction in the number of setae and spines of the swimming legs. Both species differ from the females of other species (viz. $P$. rapiens, $P$. peruanus and $P$. magnus) and from males described herein, by the following derived character states: presence of an outer spine on enp-3 of P1 (developed as a long seta in most known species; a strong spine is also present in P. magnus), loss of the inner setae of $\mathrm{P} 2-\mathrm{P} 4$ exp-1 (present in all species; in $P$. rapiens the exp-1 of $\mathrm{P} 4$ lacks the inner seta), loss of proximalmost outer spine of exp-3 of P2-P4, loss of proximalmost inner seta of enp-3 P3 and inner setae of exp-2-3 and enp-1-3 of P2-P4 short (very long in the other species).

Parameiropsis amphitriteae sp. $\mathrm{n}$. differs from $P$. antennafortis and also from the other species by the reduction in size of exp and enp segments of P1 (quadrate or rounded in $P$. amphitriteae sp. n., rectangular in other species), inner distal seta of enp-3 of P1 displaced to a subdistal position (distal in other species), distal outer seta of enp-3 of P1 transformed into a strong, bipinate and distal spine (long and flexible seta on the herein described males; transformed into a long spine with outer spinules and inner setules in $P$. magnus and $P$. antennafortis), distal inner seta of exp-3 P4 transformed into a spine (developed as a seta in the other species), reduced size of the exp lobe of P5 (well developed in the other species), furcal rami with longitudinal row of spinules along the inner margin (not ornamented in the other species) and strongly developed furcal seta III (normally developed in the other species). Furthermore, $P$. amphitriteae sp. n. differs from other known species by the following derived character states in the mouthparts: the exp of the mandibular palp is represented by 2 setae inserted on a basal bud (exp 1-segmented in the other species; the exp is fused to the basis in P. senckenbergi $\mathrm{sp} . \mathrm{n}$. but is still distinctly enlarged), exp of Mx1 represented by 1 seta inserted on a short lobe (all species have a well-developed 

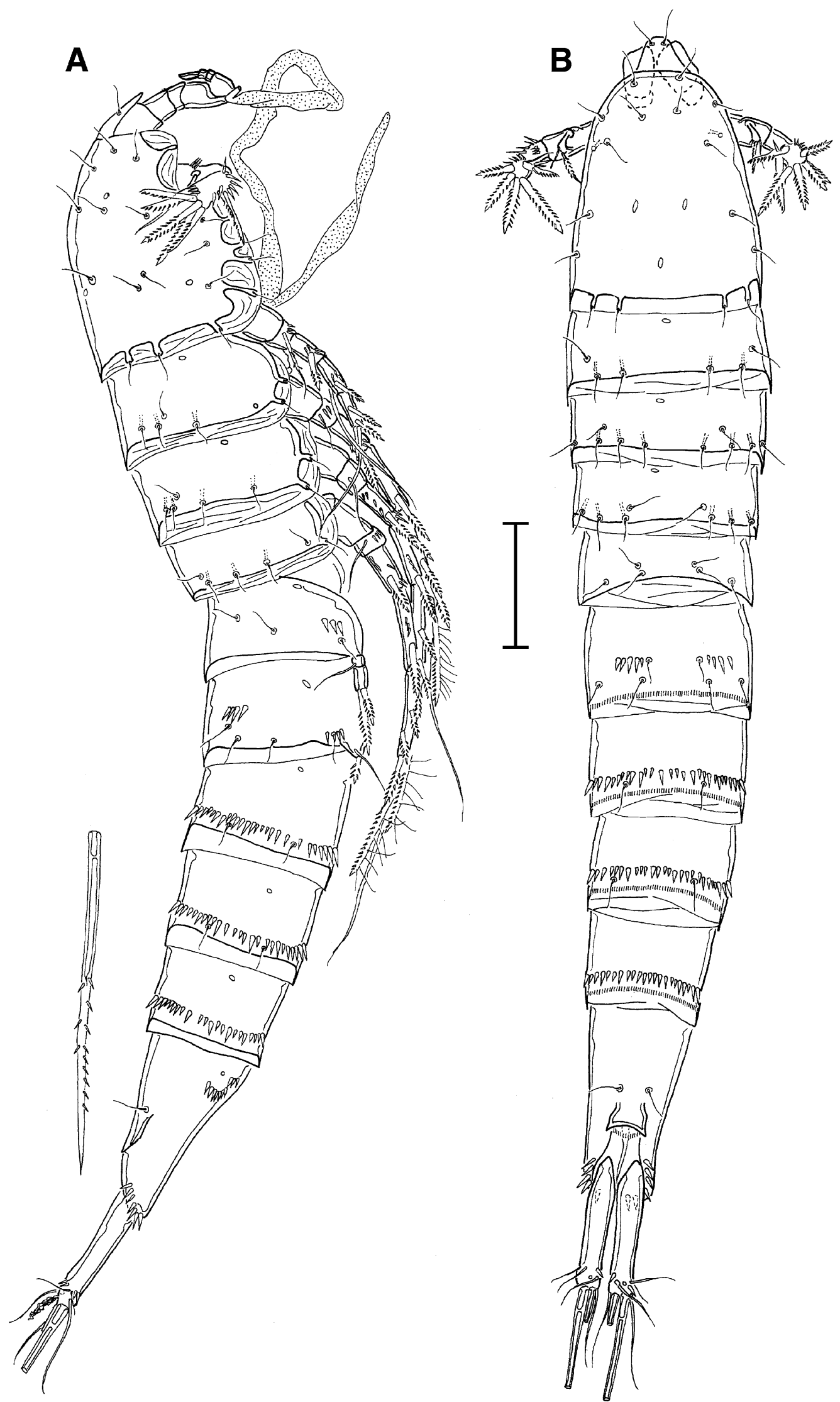

Fig. 16 Parameiropsis senckenbergi sp. n., holotype, male, SMF 32045: $A=$ lateral habitus; $B=$ dorsal habitus. Scale $=100 \mu \mathrm{m}$ 
Fig. 17 Parameiropsis senckenbergi sp. n., holotype, male, SMF 32045: $A=$ dorsal view of telson with furca; $B=$ labium. Scale $=50 \mu \mathrm{m}$
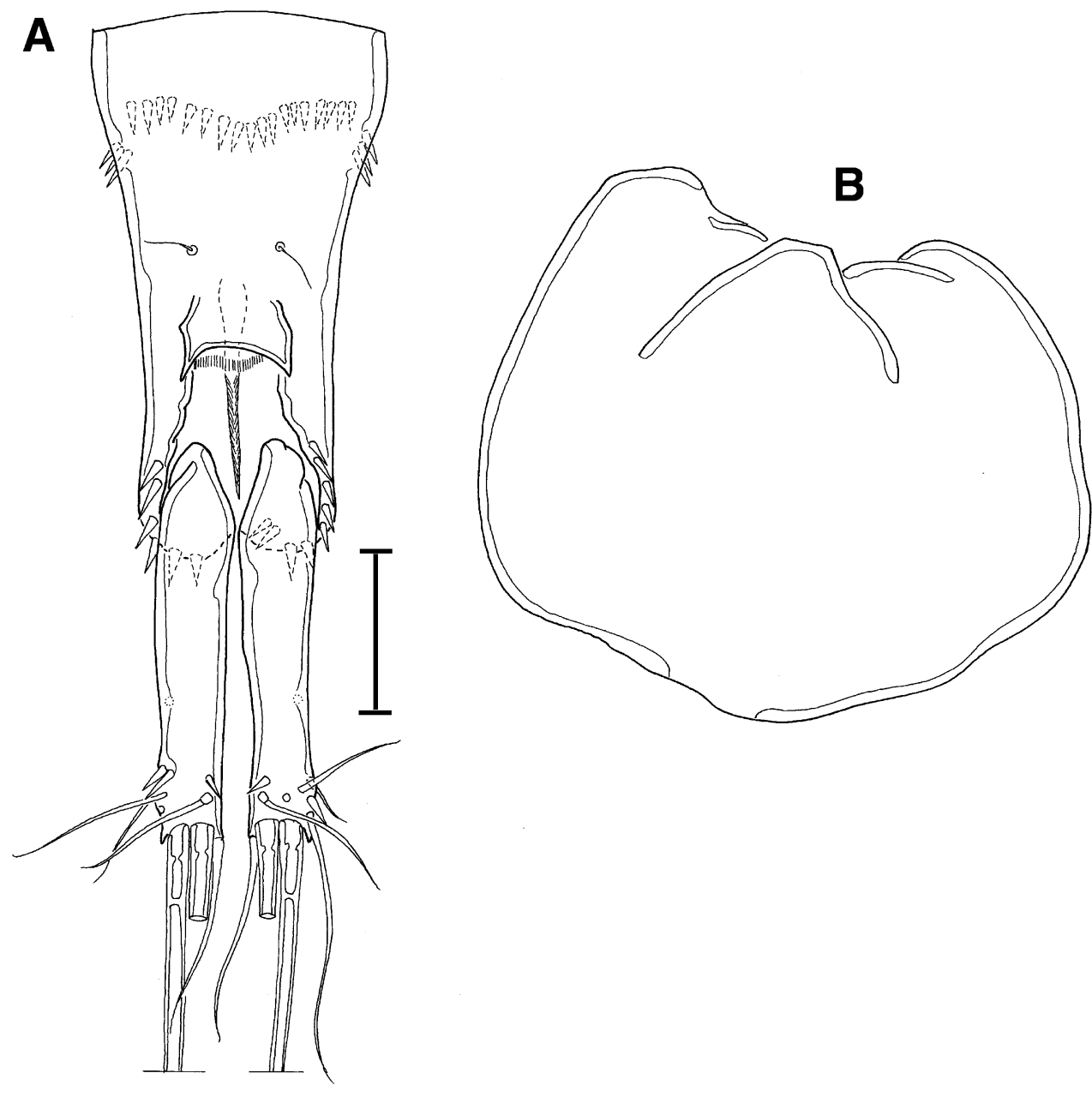

exp, with 1 seta in $P$. magnus, $P$. peruanus, $P$. rapiens and $P$. antennafortis, and being distinctly unisegmented in all species, except in $P$. senckenbergi sp. n. and P. magnus; 2 setae are present in $P$. poseidonicus sp.n, $P$. neptuni sp. n. and $P$. senckenbergi sp. n.), coxa of Mx1 with 3 setae (the same number as in $P$. poseidonicus sp. n. and $P$. antennafortis, but with more setae in the other species; data for $P$. peruanus are unavailable; Becker (1974) described 2 setae in $P$. rapiens, we could not verify the veracity of this information since the type material is not available); the enp- 2 of $\mathrm{Mx} 2$ is represented by 2 setae (loss of segmentation) inserted on the enp-1, as in P. antennafortis (setae inserted on a small lobe or unisegmented enp in the other species; given the atrophy of $\mathrm{Mx} 2$ in $P$. neptuni sp. n. and $P$. senckenbergi sp. n., this character cannot be assessed); Mxp claw strongly developed with strong spinular ornamentation (less developed in $P$. rapiens, $P$. peruanus, $P$. poseidonicus sp. n. and $P$. antennafortis; same character appears in P. magnus; it could not be assessed neither in $P$. senckenbergi sp. n. nor in $P$. neptuni sp. n.).

Other clear differences can be seen among the males described here and the known females of Parameiropsis species. However, due to the absence of descriptions of both sexes of the same species within Parameiropsis, it is difficult to be certain to what level the observed differences are phylogenetically important, or if they are the result of sexual dimorphism within this group.

In accordance with Becker (1972), certain plesiomorphic characters indicate that $P$. peruanus could be a representative of a basal lineage within the genus. Becker (1972) mentioned the distinctly separated basis of A2 and the characteristic P5 with a 1-segmented exp (also present in $P$. poseidonicus sp. n. and P. senckenbergi sp. n.). However, due to the absence of males and without having inspected the type material, it is quite difficult to hypothesize its phylogenetic position without any typological assumption. The same problem arises when trying to depict the phylogenetic relationship between the species described by Becker (1974) and Itô (1983), and the species described herein.

The inspection of the P1-P5 and mouthparts armature has not been very helpful, to elucidate neither the phylogenetic position of any species within the genus (except for $P$. amphitriteae sp. n. and $P$. antennafortis) nor the position of the genus within Harpacticoida. In order to solve these problems, a better knowledge about the morphological diversity within this group is necessary. This can be 
Fig. 18 Parameiropsis senckenbergi sp. n., holotype, male, SMF 32045: $A=$ dorsal view of rostrum and unarmed antennule in a geniculate position; $B-$ $F=$ segments of antennule disarticulated, showing the arrangement of setae, spines and aesthetascs on each segment. $B=$ segments $1-3 ; C=$ segments $3-4 ; D=$ segment 5 ;

$E=$ segment $6 ; F=$ segments 7 9. Scale $=50 \mu \mathrm{m}$

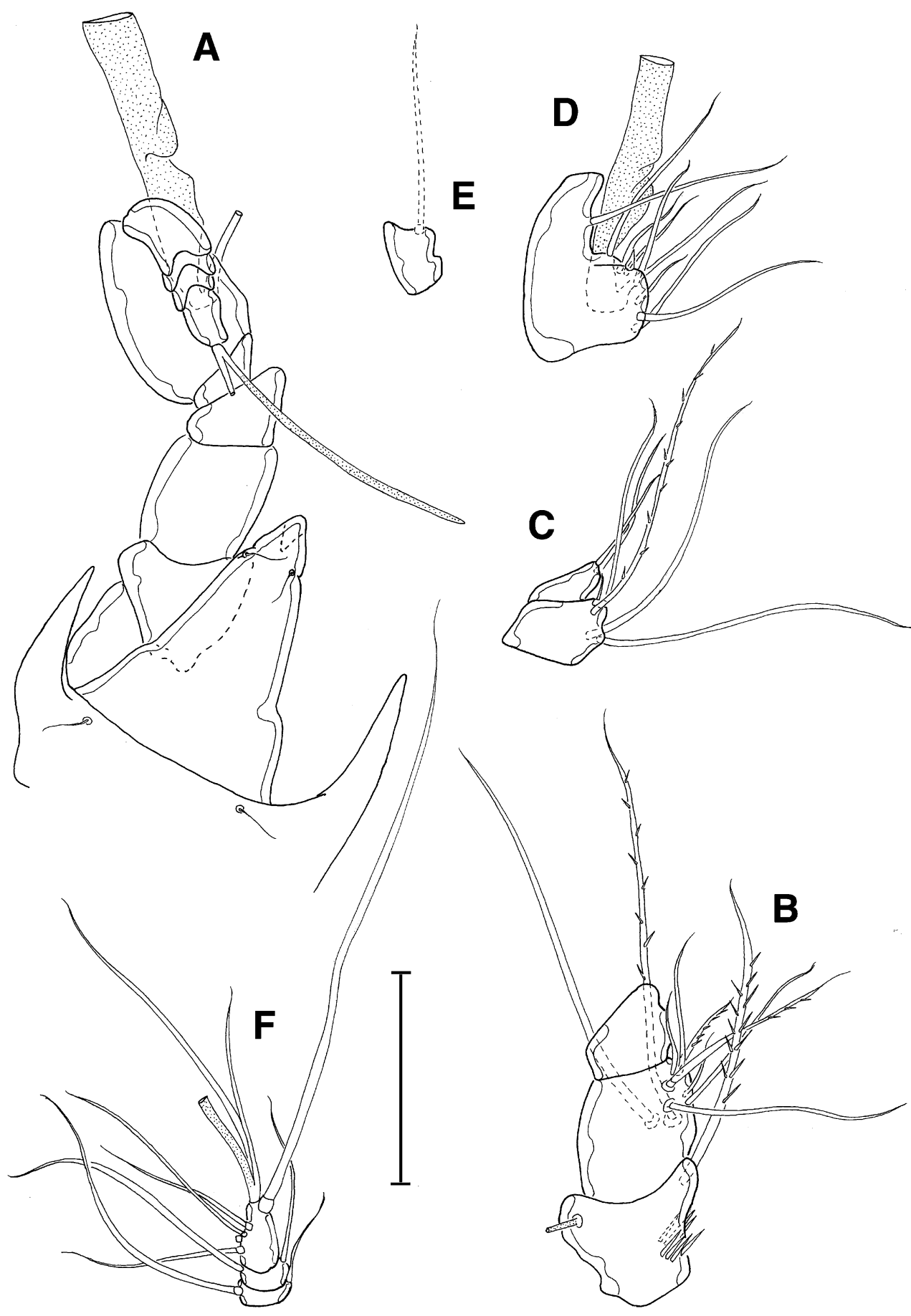

achieved through the investigation of other geographical regions and the description of the males and females of other new species.

Position of Parameiropsis within Harpacticoida: the problem around Ameiridae

The systematic position and species composition of the family Ameiridae has been a matter of discussion in the past (viz. Boeck 1865, 1872, Brady 1880; Canu 1892; Sars
1906, 1907; Scott 1909; Chappuis 1927; Monard 1927; Gurney 1932; Lang 1936, 1944, 1948). For example, members of this family have already been included in the families Harpacticidae Sars, 1904 (Boeck 1872), Miraciidae Dana, 1846 sensu Willen (2002) (Brady 1880; Canu 1892) and Canthocamptidae Sars, 1906 (Sars 1906; Scott 1909). The family itself contained members of different harpacticoid families, such as Thalestridae Sars, 1907 (Monard 1927), Tisbidae Stebbing, 1910 (Lilljeborg 1853) and Argestidae (Lang 1936; Becker 1974). Historically, its 


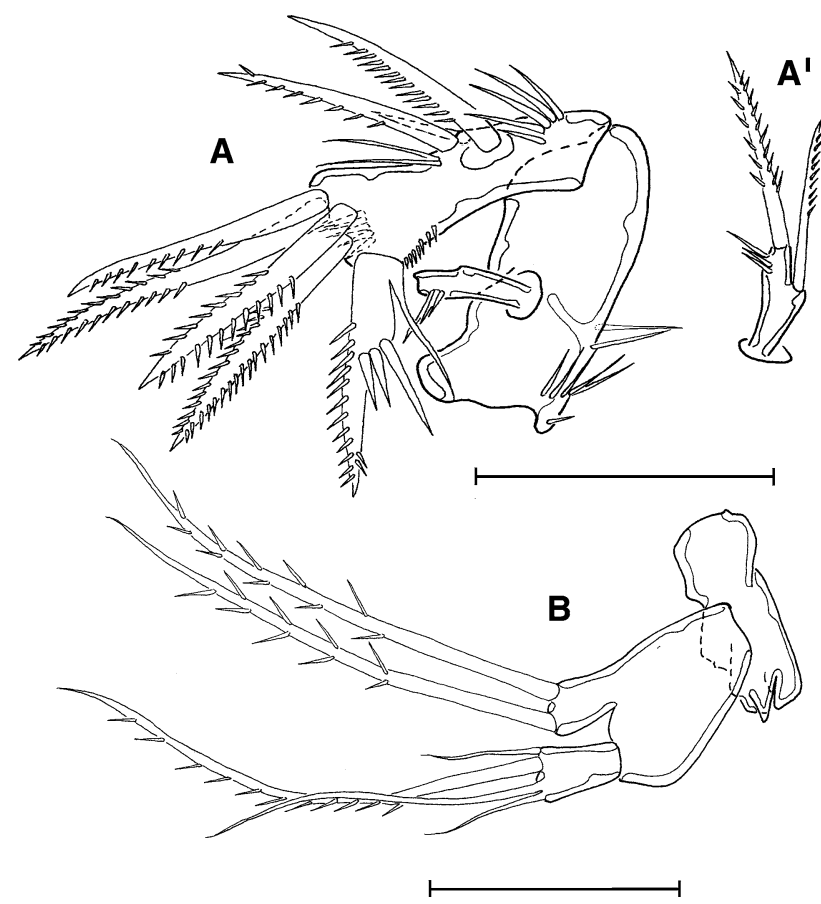

Fig. 19 Parameiropsis senckenbergi sp. n., holotype, male, SMF 32045: $A=\mathrm{A} 2 ; A^{\prime}=$ antennary exp; $B=$ Md. Scale $=50 \mu \mathrm{m}$

taxonomic composition is in a state of flux (i.e. Becker 1972, 1974; Fiers 1990; Martínez Arbizu and Moura 1994; Willen 2000; Lee and Huys 2002; Seifried 2003; Huys et al. 2009).

Nowadays, the family Ameiridae is composed of about 300 species accommodated in 41 genera (Huys et al. (2009) for the inclusion of Argestigens and Cancrincolidae within Ameiridae) and two subfamilies. The monophyly of the family is not well supported. The family is notorious for its numerous ill-defined genera, and the fine-level systematics of the group is considered a taxonomic nightmare by many researchers (Conroy-Dalton and Huys 1997). Several genera are only known from female specimens, and the whole family deserves a revision, with a detailed description of unknown males and full illustration of the mouthparts.

According to Becker (1972), the genus Parameiropsis would belong to the family Ameiridae, occupying a basal position within the subfamily Ameirinae Lang, 1944. According to this author, the placement of Parameiropsis within Ameiridae would be supported by the "astonishing" correlation between the general morphology of Parameiropsis and the hypothesis of the Ameiridae "Ursprungsform" (original shape) proposed by Lang (1948). Within Ameiridae, Parameiropsis would share a common ancestry with Ameiropsis being an offshoot prior to the transformation of the P1 enp into a prehensile structure.

Lang (1944) proposed the following diagnostic characters for the family:

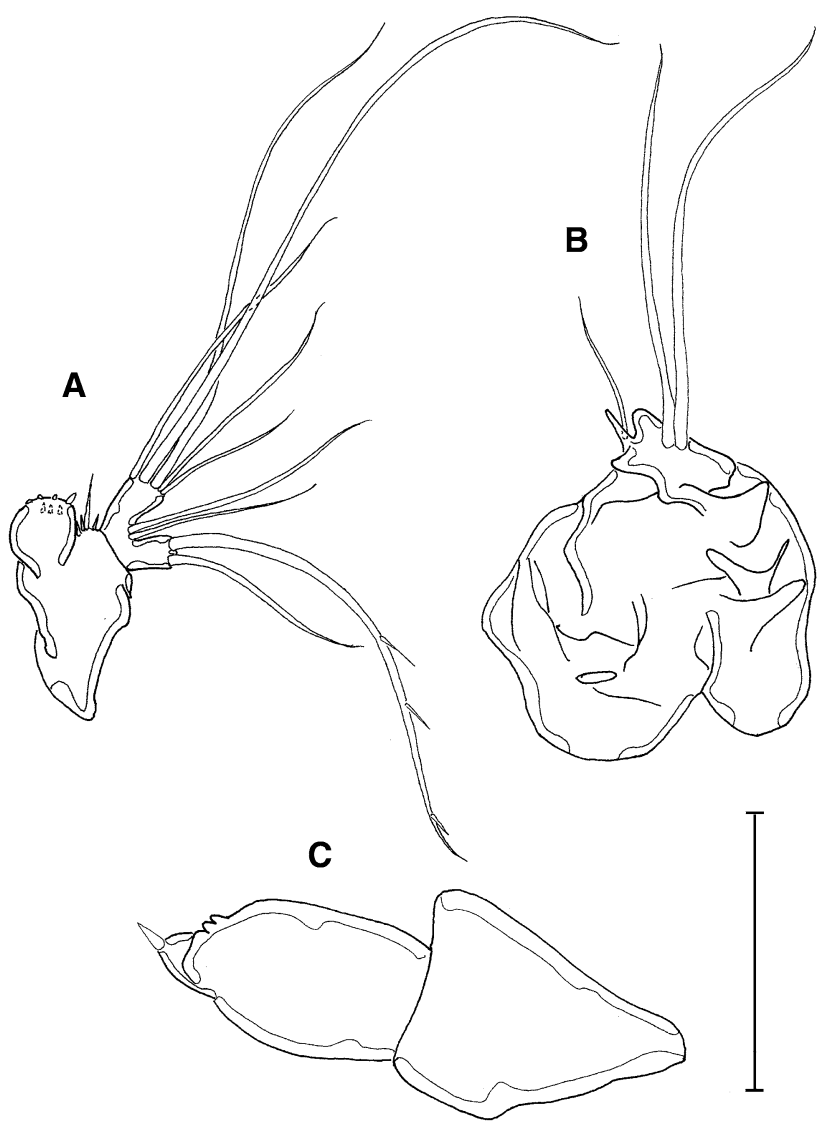

Fig. 20 Parameiropsis senckenbergi sp. n., holotype, male, SMF 32045: $A=\mathrm{Mx} 1 ; B=\mathrm{Mx} 2 ; C=$ Mxp. Scale $=50 \mu \mathrm{m}$

Body elongated, equally wide or with clear distinction between prosome and urosome. Rostrum well defined or fused to cephalothorax. Furca variable in size. Female A1 from 5- to 9-segmented. Male A1 haplocer. A2 generally with an unarmed basis and a 2-segmented exp. Md with a completely developed basis, exp sometimes present, but generally absent, enp always present and well defined. Mx1 well developed, enp and exp generally reduced, epipodite fused. Mx2 with 2 or 3 endites. Mxp well developed, prehensile. P1 exp with 1-3 segments, enp 2-3-segmented. Exp and enp of P2-P4 generally 3-segmented, exp sometimes 2-segmented, enp sometimes 1- or 2-segmented. P2-P4 generally without sexual dimorphism; however, sometimes the outer spine of the exp 3 of P3 is sexually dimorphic. P5 very variable. Inner seta of the basis of P1 transformed in males into a spine-like structure. Eyes generally present and visible. Seminal receptacle without or with a very strong lateral grove.

Lang's diagnosis for Ameiridae is a mixture of plesiomorphic characters and some others that appeared independently 
Fig. 21 Parameiropsis senckenbergi $\mathrm{sp}$. n., holotype, male, SMF 32045: $A=\mathrm{P} 1 ; B=\mathrm{P} 2$. Scale $=50 \mu \mathrm{m}$

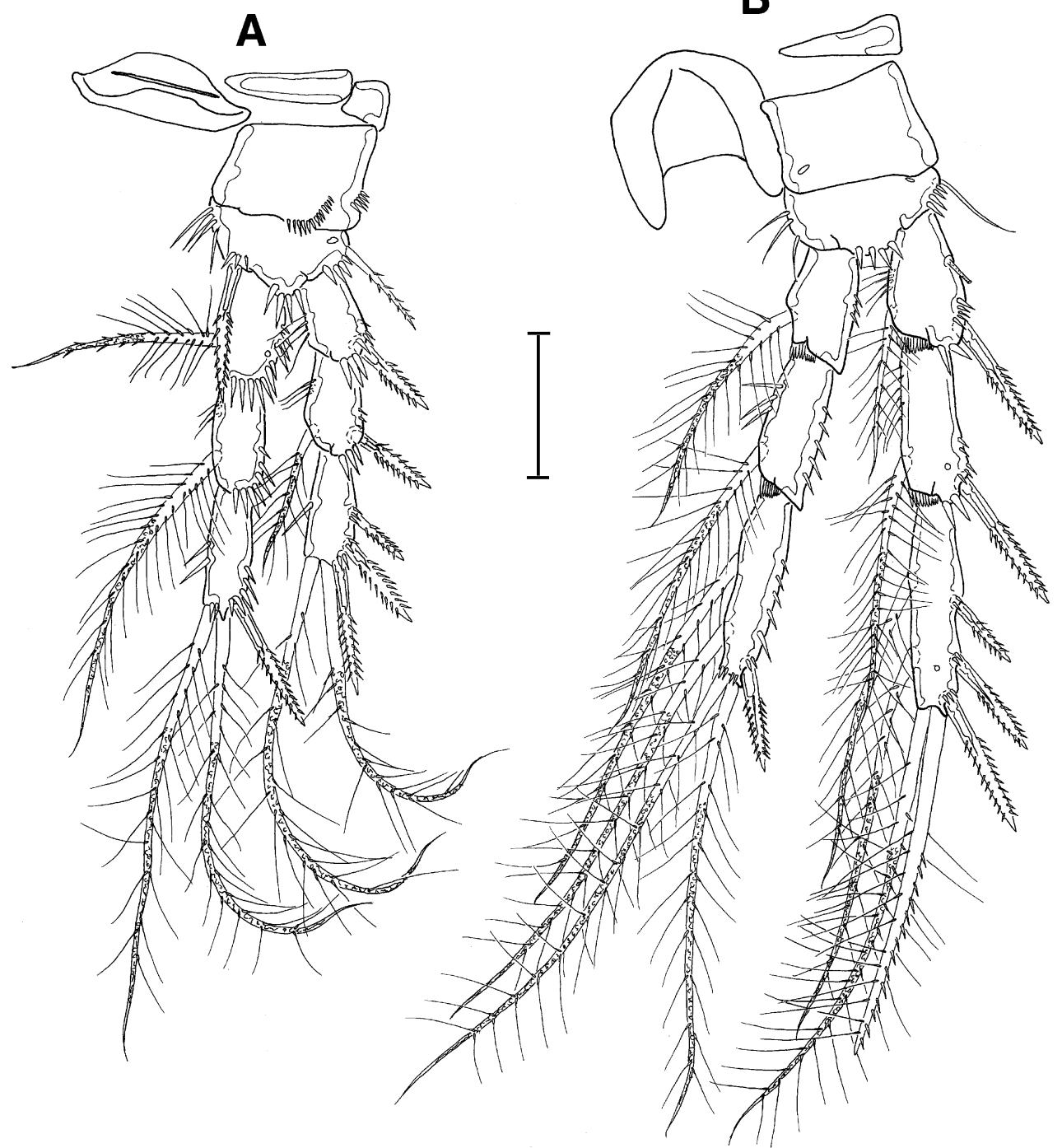

within Ameiridae and in other families of Harpacticoida. Only very few of these characters are phylogenetically informative. Consequently, the family diagnosis is not unequivocal. Therefore, the inclusion of certain genera and species within Ameiridae is supported more by typological assumptions than by a well-founded phylogenetic reasoning. The only characters that could support the inclusion of Parameiropsis within Ameiridae are the absence of an abexopodal seta on the antennary basis and the presence of a 1-segmented A2 exp with 2 setae. However, this character appeared several times within Harpacticoida and, on the absence of other potential synapomorphies, the inclusion of Parameiropsis within Ameiridae is uncertain.

The presence of a dimorphic spine (with a hook on its extremity) on the inner margin of the P1 basis in males is common within Ameiridae. Boxshall and Halsey (2004) considered this character to be present in all Ameiridae, except for some neotenic genera (such as Psammonitocrella, Huys 2009) and a few deep-water genera (like Malacopsyllus, Anoplosomella and Parameiropsis). The absence of this kind of sexual dimorphism in the inner basal seta of the male P1 in Parameiropsis is an argument in favour of the exclusion of this genus from the crown group Ameirinae and probably from the Ameiridae. However, the morphology of the segments and armature elements of P1 seems more informative to us. In the groundpattern of the Podogennonta (Martínez Arbizu and Moura 1994; Willen 2000), the enp of $P 1$ is prehensile, with the first segment being much longer than the second and third segments, and the third segment being armed with an outer claw-like seta, superimposing one geniculated outer terminal seta and a minute inner terminal seta (Fig. 30A). The absence of these characters in Parameiropsis ( $\mathrm{P} 1$ not prehensile, and the 
Fig. 22 Parameiropsis senckenbergi sp. n., holotype, male, SMF 32045: $A=\mathrm{P} 3 ; B=\mathrm{P} 4$. Scale $=50 \mu \mathrm{m}$

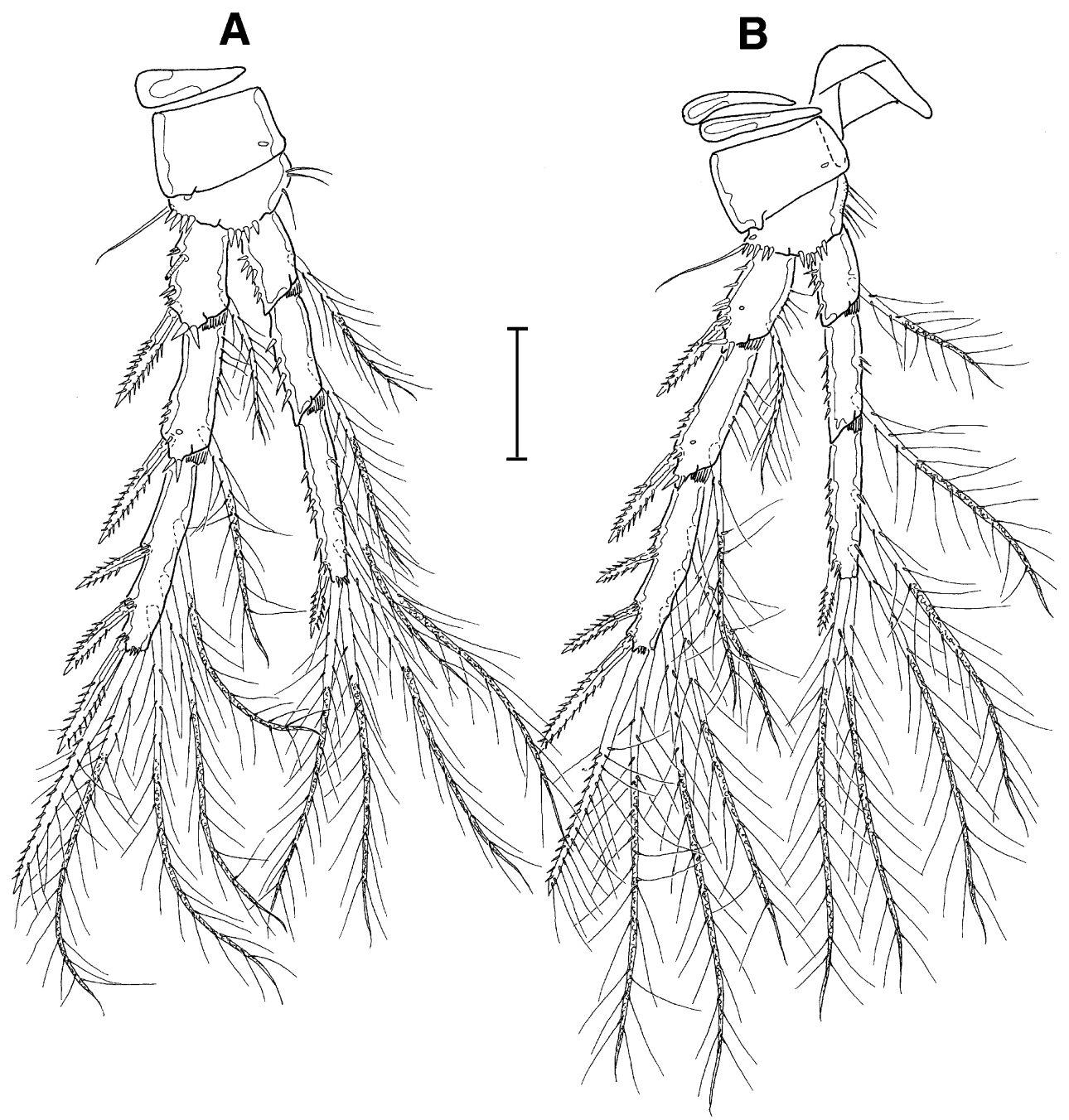

third endopodal segment with 3 unmodified setae) even precludes the inclusion of Parameiropsis into the Podogennonta.

According to Corgosinho and Gheerardyn (2009), in $P$. antennafortis, the outer spine of enp-3 of P1 is transformed into a unipinnate spine (ornamented only along the outer margin), the outer terminal seta is transformed into a rigid spiniform seta, and the inner terminal seta is naked and much reduced in size. Given the more derived position of $P$. antennafortis within Parameiropsis, the hypothesis of a Podogennonta P1 at the groundpattern of the genus Parameiropsis is not parsimonious.

In order to support the exclusion of Parameiropsis from Ameiridae, we critically analyse here the subfamilies Stenocopiinae and Ameirinae.

The subfamilies Ameirinae and Stenocopiinae

The family Ameiridae is composed of the subfamily Ameirinae, which contains most of the species, and the subfamily Stenocopiinae (represented by the genera Stenocopia
Sars, 1907, Anoplosomella and Malacopsyllus). A mixture of plesiomorphies and homoplastic characters form Lang's (1944) diagnoses for both subfamilies. Although the fact that Stenocopiinae species are diagnosed by the elongated first segment of A1 and the transverse elongation of the bases of P2-P4, there are strong arguments derived from the analysis of the morphology of $\mathrm{A} 1, \mathrm{Mx} 2$ and $\mathrm{Md}$ that clearly show the polyphyletic condition of this group.

Within Stenocopiinae, only Stenocopia has an elongated first A1 segment with a distal inner seta (Fig. 30I), whereas the first segment of A1 unarmed in Anoplosomella (Fig. 30H) and Malacopsyllus (Fig. 30G). The absence of this armature in S. reducta Cottarelli, Saporito and Puccetti, 1986 is probably a derived condition or a slip of the pen. Other important characters that we use to distinguish Anoplosomella and Malacopsyllus from Ameiridae are expressed on Mx2. In the species composing these genera, the distal basal endite of Mx2 is armed with one very strong spine, approximately as long as enp-1 claw. In addition, one very strong spine (almost as long as the distal endite spine and the claw of the basis) inserts ventro-laterally or 
Fig. 23 Parameiropsis

senckenbergi sp. n., holotype, male, SMF 32045: ventral view of urosome showing P5-P6.

Scale $=50 \mu \mathrm{m}$

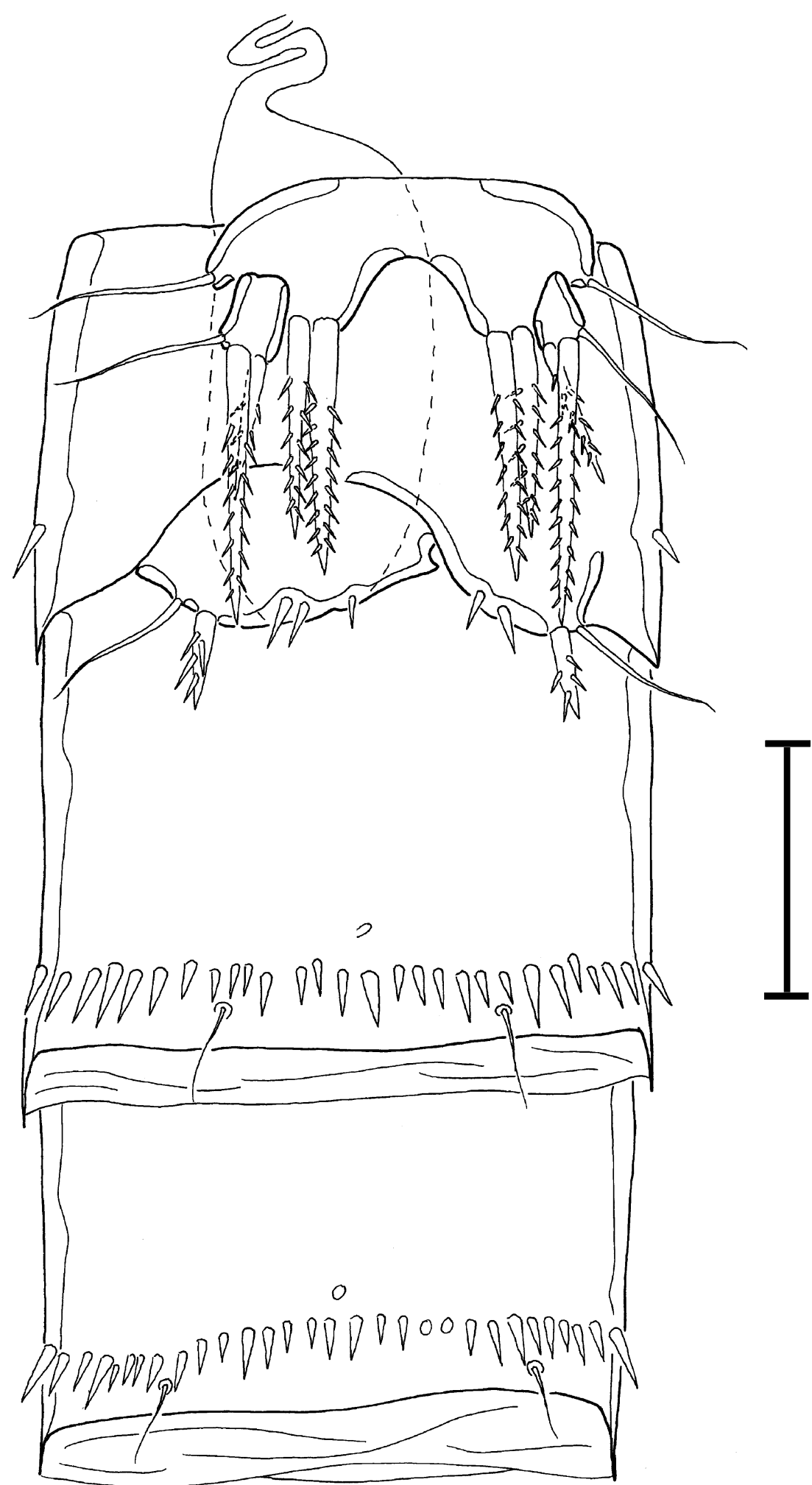

dorso-laterally to the enp-1 claw, conferring a scissor-shape to the distal elements (Fig. 30B, C for Anoplosomella and Malacopsyllus, respectively). This condition is absent in Stenocopia (Fig. 30E). Finally, within Stenocopiinae, only Anoplosomella and Malacopsyllus share the shape of the
Md, with the cutting edge of the gnathobasis armed with an oral and an aboral denticulate cutting plate (Fig. 30J, K1, $\mathrm{K} 2$ ), with a serrated or brush-shaped spine inserted in between (Fig. 30K1, K2a). It is very important to mention here that the modifications, observed in Anoplosomella and 
Fig. 24 Parameiropsis amphitriteae sp. n., holotype, female, SMF 32046: $A$ = dorsal habitus; $B=$ lateral habitus. Scale $=100 \mu \mathrm{m}$
A

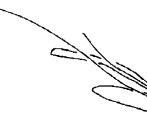

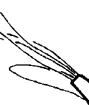

$I$

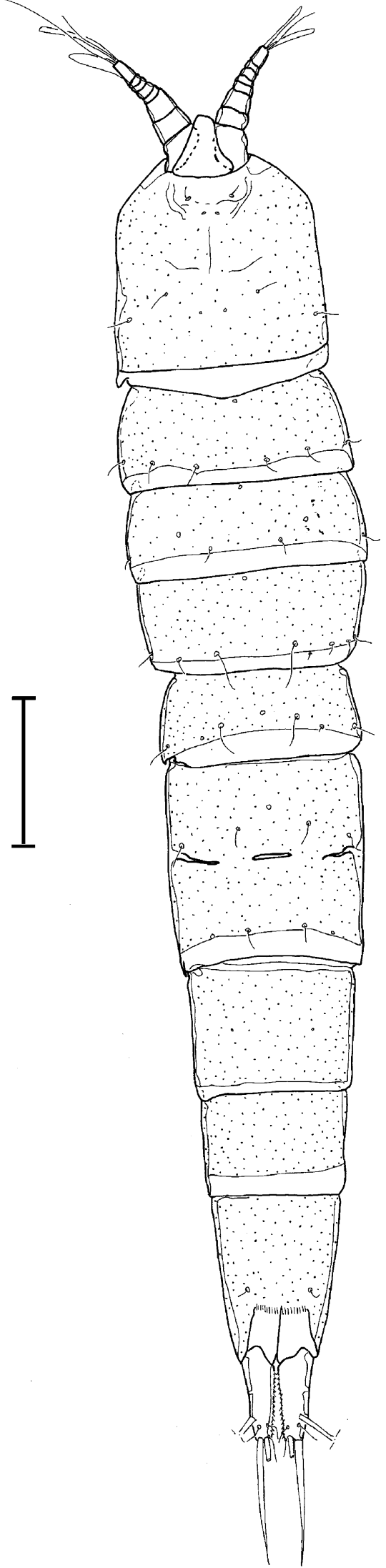

B

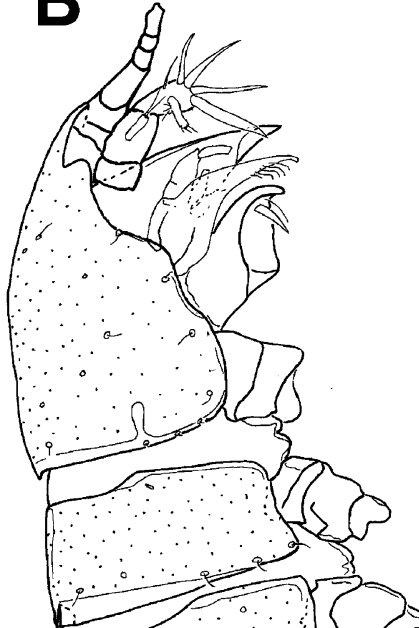




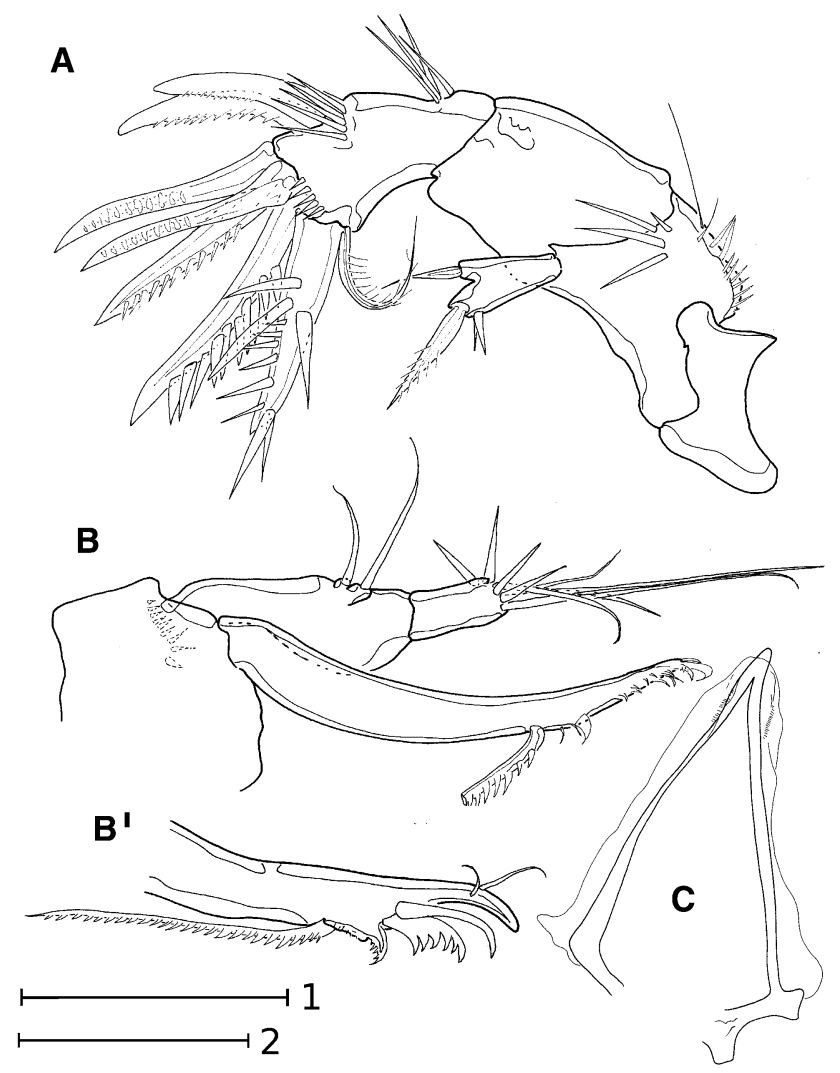

Fig. 25 Parameiropsis amphitriteae sp. n., holotype, female, SMF 32046: $A=$ antenna; $B=\mathrm{Md} ; B^{\prime}=$ detail of $\mathrm{Md}$ gnathobasis; $C=$ labrum. Scale $1\left(A, B, B^{\prime}\right)$ and $2(C)=50 \mu \mathrm{m}$

in Malacopsyllus, are absent in all Ameirinae and in Stenocopia. However, the same Mx2 morphology described earlier is present only in Argestidae. Additionally, the same kind of first antennular segment and mandibular gnathobasis, described here for Anoplosomella and Malacopsyllus, also appears within Argestidae in Eurycletodes Scott, 1909 (A1 in Fig. 30F; Md in Fig. 30L1-L3) and in a group closely related to it (K.H. George personal communication). Therefore, Anoplosomella and Malacopsyllus are formally removed from Stenocopiinae and placed phylogenetically within Argestidae. Within this family, Anoplosomella and Malacopsyllus would be closely related to Eurycletodes, or to a larger group around it, sharing the apomorphic condition of A1 (with a long unarmed first segment, Fig. 30F-H), shape and armature of $\mathrm{Mx} 2$ (Fig. 30B-D), shape of the cutting edge of the Md gnathobasis (Fig. 30J-L), transverse elongation of bases of P1-P4, and the shape of body and telson.

The name-bearing type for the subfamily Stenocopiinae is the genus Stenocopia. This is a typical Ameiridae genus, with a sexually dimorphic spine on the inner margin of the basis of the male P1 and a Podogennonta P1 enp (Fig. 30A). In Stenocopia (Fig 30E) and many other genera of Ameiridae, the proximal basal endite of Mx2 has what
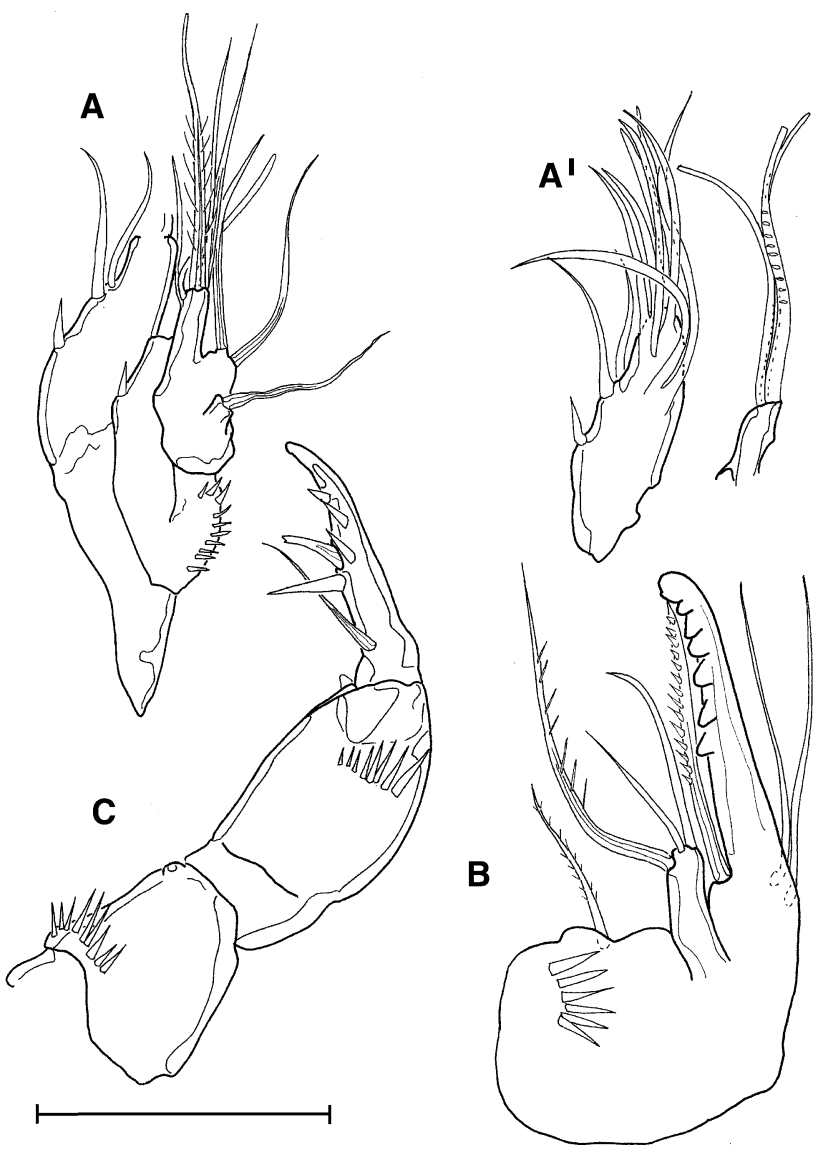

Fig. 26 Parameiropsis amphitriteae sp. n., holotype, female, SMF 32046: $A=\mathrm{Mx} 1 ; A^{\prime}=$ detail of Mx1 praecoxa and coxal endite; $B=\mathrm{Mx} ; C=$ Mxp. Scale $=50 \mu \mathrm{m}$

we consider a groundpattern autapomorphy for the family. It is bilobed, comprised by a spine proximally fused to the endite, followed by a flexible distal seta and a distal, unarmed bulge. Additionally, the taxon Stenocopiinae satisfies all ICZN (1999) requirements to be considered valid. Therefore, we argue in favour of its monophyly after the relocation of Anoplosomella and Malacopsyllus to Argestidae. After these taxonomical adjustments, the monophyly of the subfamily Stenocopiinae is supported by at least the following characters: P2-P4 bases transversely elongated (appearing independently within Harpacticoida in the Argestidae and Ancorabolidae Scott, 1909), and the elongated first segment of A1 with a distal seta on the inner margin (which appeared independently in Ancorabolidae).

Parameiropsis does not show any of the putative apomorphies mentioned earlier. On the contrary, the first segment of the A1 of Parameiropsis is short, and the bases of P2-P4 are not transversely elongated. Therefore, the inclusion of Parameiropsis within Stenocopiinae is not supported.

For the subfamily Ameirinae, the name-bearing type is the genus Ameira Boeck, 1864, which is also a typical 
Fig. 27 Parameiropsis amphitriteae sp. n., holotype, female, SMF 32046: $A=\mathrm{P} 1 ; B=\mathrm{P} 2$; $C=$ ventral view of telson and furca; $D=$ P5. Scale $=50 \mu \mathrm{m}$

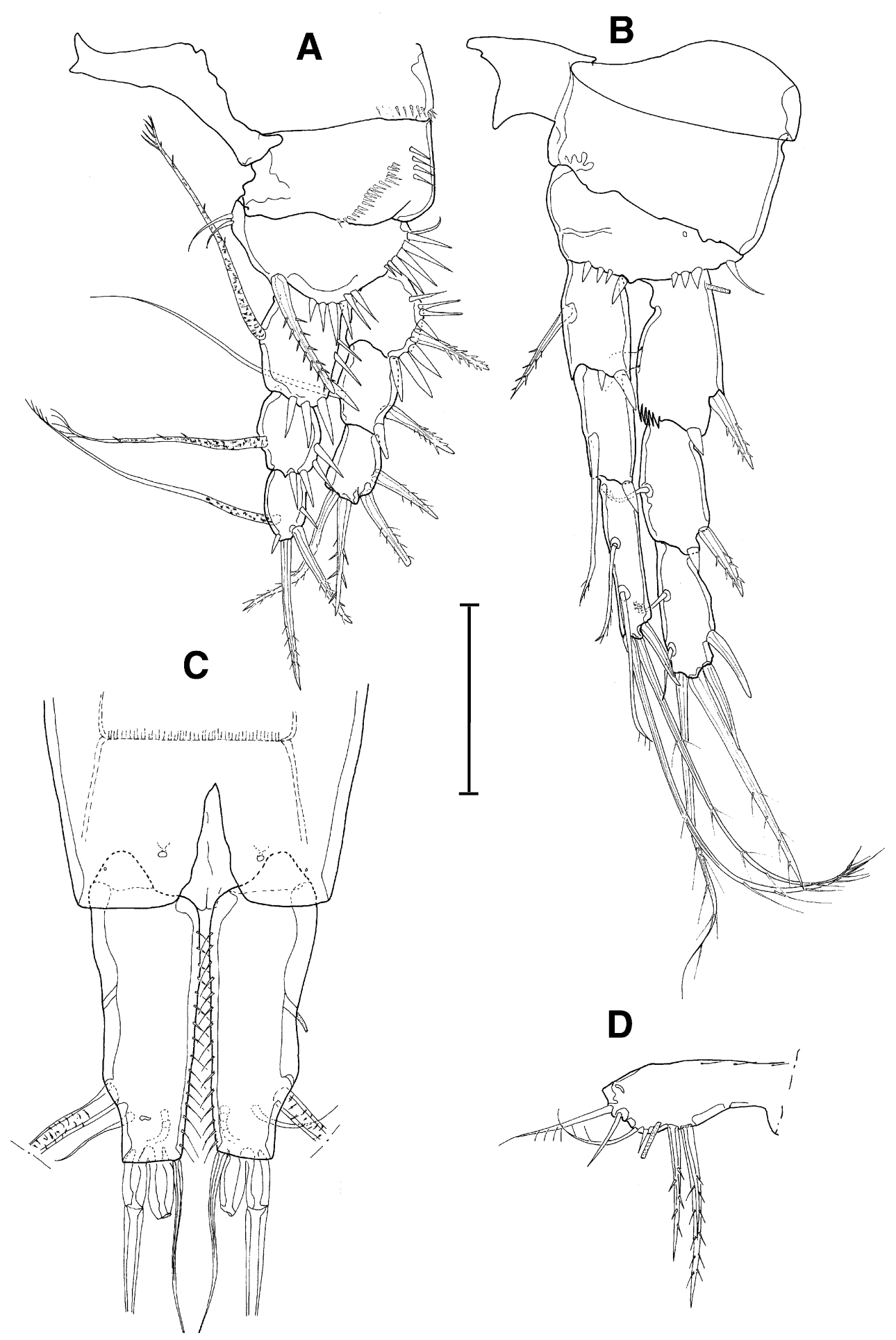

Ameiridae genus, with the so-called Podogennonta enp of P1 and the modified spine on the inner margin of male P1 basis. However, the Podogennonta-type P1 is plesiomorphic for Ameiridae and cannot be used to define the Ameirinae as a monophylum. In addition, a modified spine in the inner margin of the male P1 is also present in Stenocopia. Therefore, this character cannot be used to define the sub- family Ameirinae. In fact, we failed to find a character to define Ameirinae as a monophylum. For example, the observation of the diagnosis proposed by Lang (1944) for this subfamily does not reveal a single autapomorphy for the group.

Within Ameirinae, only some Sarsameira Wilson, 1924 species do not have a Podogennonta P1. It is not within the 


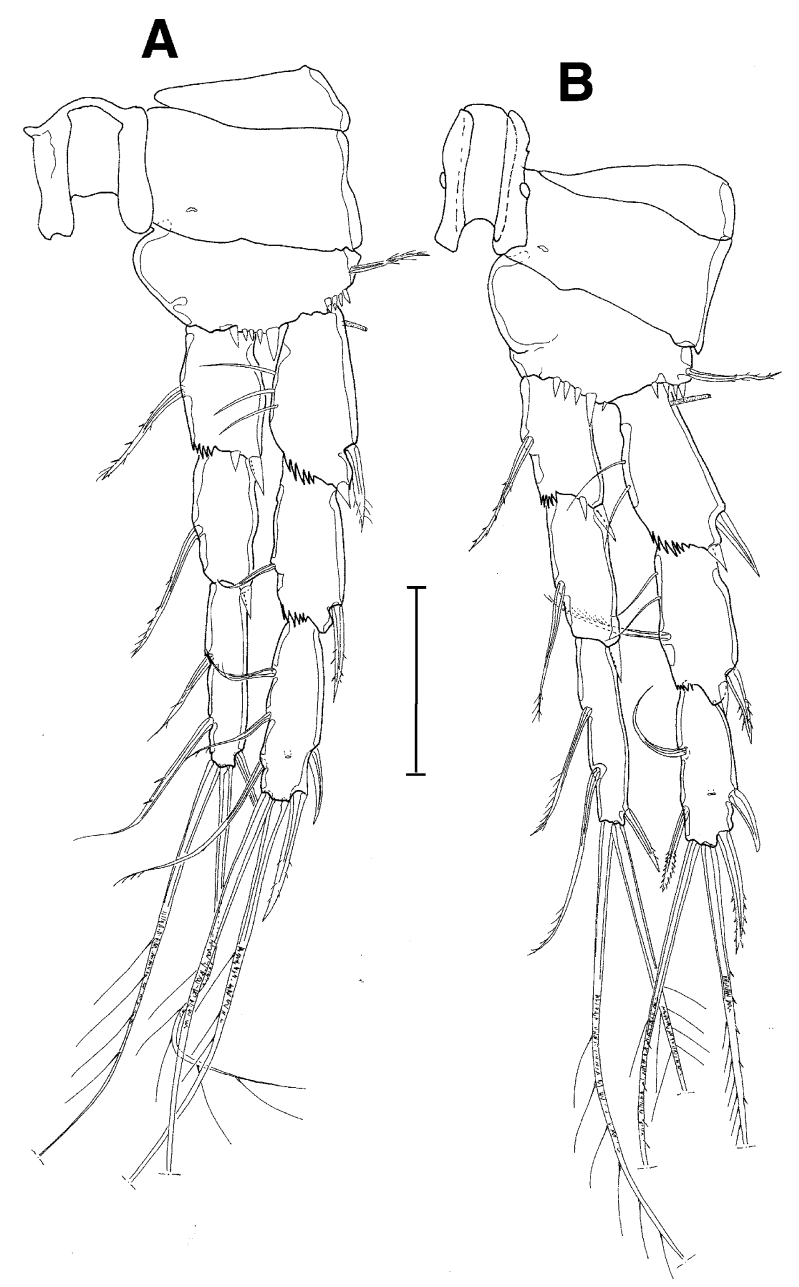

Fig. 28 Parameiropsis amphitriteae sp. n., holotype, female, SMF 32046: $A=\mathrm{P} 3 ; B=\mathrm{P} 4$. Scale $=50 \mu \mathrm{m}$

scope of this paper to discuss the monophyly of this problematic genus. However, our observations of some undescribed material revealed that in a group closely related to the type species of Sarsameira (viz. Sarsameira parva (Boeck, 1873)), the males have the typical dimorphic Ameiridae spine on the inner margin of the P1 basis and the Ameiridae Mx2 characters that we discussed earlier. Parameiropsis does not have any of the autapomorphic characters mentioned earlier for Ameiridae, namely, the dimorphic Ameiridae spine on the inner margin of the male $\mathrm{P} 1$ basis, nor the Mx2 autapomorphies. Therefore, in face of the current evidence, we favour the exclusion of Parameiropsis from this family.

The problem around Argestidae

Becker (1974) hypothesized a possible close relationship between Parameiropsis and the genera Argestes Sars, 1910, Parargestes Lang, 1944 and Argestigens, which he included within Ameiridae. According to Becker (1974), a close relationship of Parameiropsis with the genus Argestes is strongly supported by the following characters:

A2 with basis and 1-segmented exp; mandibular palp with 1-segmented exp and enp; Mx2 with three endites, the proximalmost reduced; a characteristic $\mathrm{P} 1$; primitive armature of the $\mathrm{P} 1-\mathrm{P} 4$ and elongated telson, the latter being longer than the two preceding urosomites.

However, the study of these genera reveals that only the presence of a 1-segmented antennary exp with at most 2 distal setae, and the absence of the abexopodal seta on antennary basis could justify their inclusion within Ameiridae. Por (1986), when establishing the family Argestidae, already included Argestes, Parargestes and Argestigens within it. We do not support the rearrangement proposed by Becker (1974), i.e. the inclusion of these argestid genera within Ameiridae, with Parameiropsis being an offshoot that diverged early in the origin of the ameirids. Argestidae and Ameiridae differ significantly as to Mx2 morphology, not sharing any of the novelties described earlier and depicted in Fig. 30B-E. Therefore, the evidence offered to here do not support the inclusion of Argestes and Parargestes within Ameiridae. The systematic position of Argestigens is discussed in the following paragraphs.

A hypothesis of close relationship among Parameiropsis, Argestes, Argestigens and Parargestes, is prejudiced by the absence of the Argestidae Mx2 characters in Parameiropsis. In Parameiropsis, the Mx2 syncoxa is fused to the basis, the proximal endite of the basis of $\mathrm{Mx} 2$ has a single seta, the distal basal endite has 3 setae, and the enp- 1 is drawn into a strong, sclerotized claw with a strong spine inserted proximally on the oral margin. The presence of 2 basal endites and 1 syncoxal endite on the Mx2 of Parameiropsis (Becker 1974) is a doubtful character and could not be verified in any of the species described here. In fact, this is a good evidence to assign Parameiropsis outside of Argestidae.

Other characters, such as the primitive armature of P1$\mathrm{P} 4$, are plesiomorphies and cannot be used to define a monophyletic unity around Argestes, Argestigens, Parargestes, Parameiropsis and the Ameiridae. Additionally, none of the species within Parameiropsis have the typically transversely elongated bases of $\mathrm{P} 2-\mathrm{P} 4$ as in the Argestidae and the rami of these limbs are not displaced to the outer margin.

Note on the monophyly of Argestidae and Ameiridae

Recently, Huys et al. (2009) assigned the genus Argestigens to Ameiridae, proposing a close relationship between Argestigens and Sarsameira. These authors based their conclusions on a molecular (18S rDNA) phylogenetic analysis 
Fig. 29 Parameiropsis amphitriteae sp. n., holotype, female, SMF 32046: $A$ = antennule;

$B=\mathrm{P} 5 ; C=$ genital field and P6. Scale $=50 \mu \mathrm{m}$

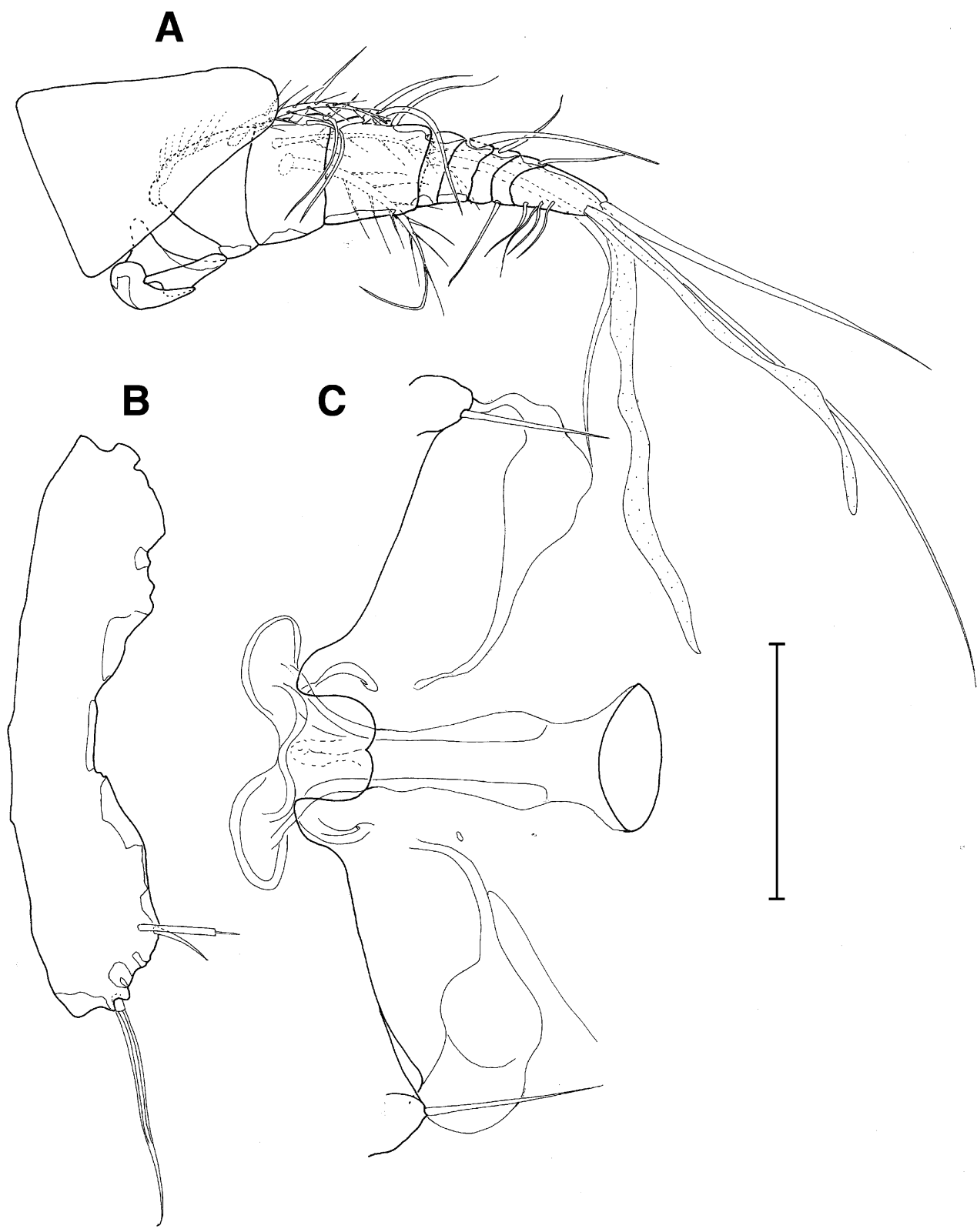

of some Copepoda species, of different families and genera (mostly Harpacticoida). They concluded that the family boundaries of both the Ameiridae and the Argestidae are not well delimited. For example, in accordance with Huys et al. (2009), Argestoides prehensilis Huys and ConroyDalton, 1997 (an Argestidae incertae sedis taxon) is an example of how ill-defined the border is between Argestidae and Ameiridae.

Our study of the families Ameiridae and Argestidae gives support to some of the conclusions by Huys et al. (2009). For example, the Mx2 of Argestigens abyssalis Becker, Noodt and Schriever, 1979 superficially resembles what is described for some Sarsameira species. Here, it is especially worth mentioning that the structure of the proximal basal endite of the Mx2 of A. abyssalis, shows what
Fig. 30 (A) Male P1 of Stenocopia sp.; (B) Mx2 of Anoplosomella sp.; (C) Mx2 of Malacopsyllus sp.; (D) Mx2 of Eurycletodes sp.; (E) Mx2 of Stenocopia sp. The arrow indicates the distal unarmed bulge of the proximal basal endite; $(F)$ first A1 segment of Eurycletodes sp.; $(G)$ first A1 segment of Malacopsyllus sp.; $(H)$ first A1 segment of Anoplosomella sp.; (I) first A1 segment of Stenocopia sp. $(J) \mathrm{Md}$ of Anoplosomella sp.; $(K 1, K 2) \mathrm{Md}$ of Malacopsyllus sp.; ( $L 1=$ lateral view; $L 2=$ aboral view; $L 3=$ aboral view) $\mathrm{Md}$ of Eurycletodes sp. $K 2 a=$ intermediate mandibular spine of Malacopsyllus sp.; $K 2 b=$ oral mandibular tooth of Malacopsyllus sp. $L 3 a=$ aboral mandibular tooth of Eurycletodes sp.; $L 3 b=$ intermediate mandibular spine of Eurycletodes sp.; $L 3 c=$ oral mandibular tooth of Eurycletodes sp. Figures out of scale

could be homologous to the distal bulge figured in several Ameiridae descriptions (arrowed in Fig. 30E) and conceivably is present in the groundpattern of this family. Moreover, the 


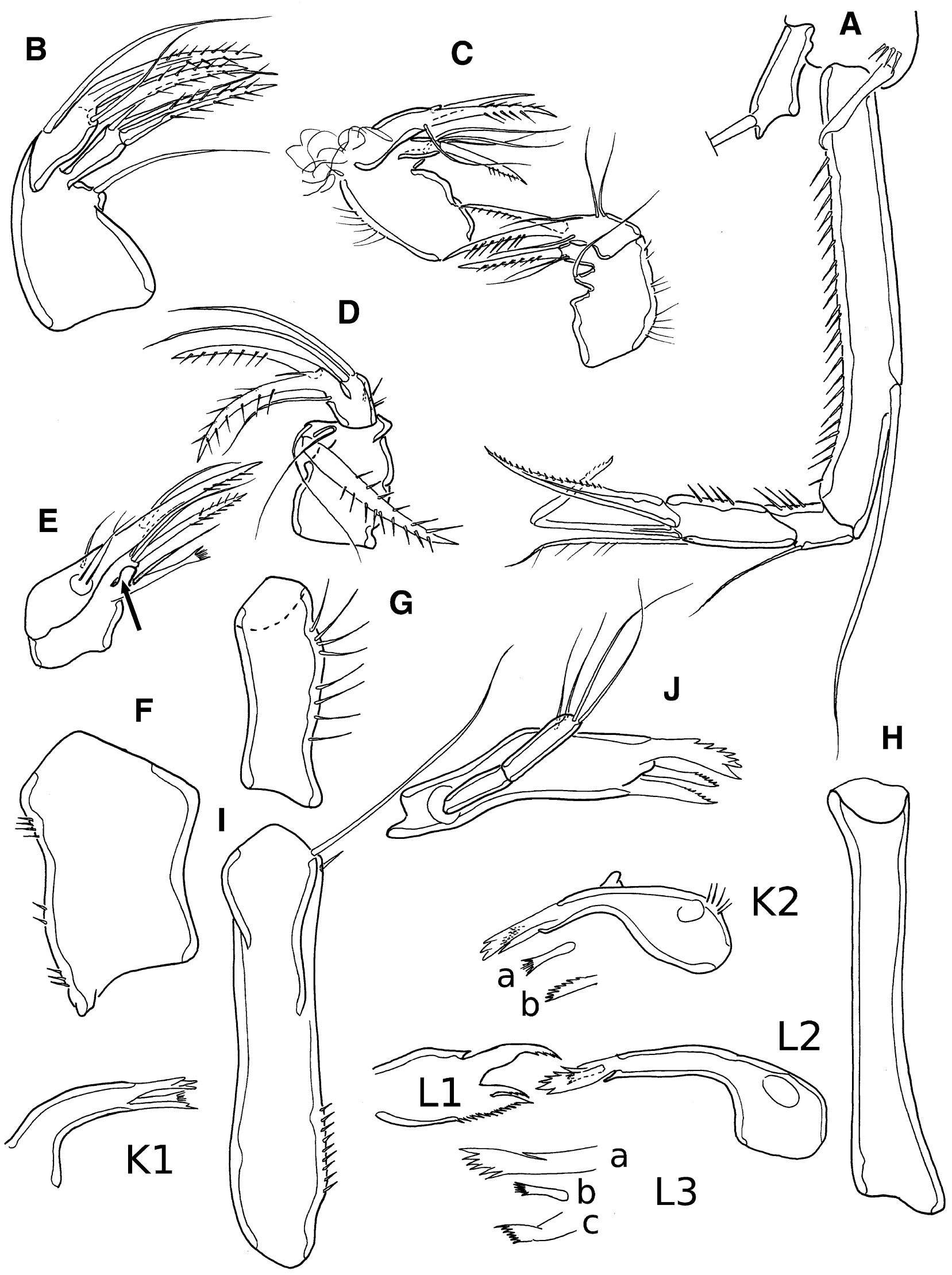


comparison of the complete description of Argestigens abyssalis, as well as the descriptions of the type species of the genera Argestigens (viz. A. uniremis Willey, 1935) and Sarsameira (viz. Sarsameira parva; see Sars 1907) gives some strength to a hypothesis of closer relationship between these genera.

However, our observations also show that Argestidae and Ameiridae can be defined by several autapomorphies present on the Mx2 and the mandibular palp. For example, Argestoides prehensilis, considered a problematic taxon of unclear position between Ameiridae and Argestidae, does not have any of the Mx2 autapomorphies proposed for Argestidae. Instead, in A. prehensilis, the accessory spine of the enp- 1 claw of Mx2 and the spine of the distal basal endite are not strongly developed as the enp- 1 claw. Likewise, some derived Ameiridae, this species does not have the distal bulge on the proximal Mx2 endite (maybe secondarily lost). In addition, the spine of the distal basal endite of the Mx2 is transformed, showing a brush-like extremity. This is a character present in several Ameiridae such as Nitocrella pescei Galassi and De Laurentiis, 1997, Ameira hyaline (Noodt, 1952), Filexilia trisetosa Conroy-Dalton and Huys 1997 and Parapseudoleptomesochra trisetosa (Krishnaswamy, 1957). In addition, it has a typical Podogennonta P1 enp, and the basis of the mandibular palp has 2 transformed spines (also present in several species within Ameiridae). It is still unclear to which level of generality the characters observed in A. prehensilis are apomorphic within Ameiridae. However, on the absence of contradictory data, here we favour its assignment to Ameiridae.

Harpacticoida contains about 4,300 species in 589 genera and 56 families (Wells 2007). It is known that the amount of sampled taxa, as well as the distinct rates of DNA mutation in different taxa, clearly affects the result of a molecularbased phylogeny (Wägele 2005; Knoop and Müller 2009). Therefore, although recognizing the existence of some putative similarities on the Mx2 in A. abyssalis and some Sarsameira species, we recommend caution on the interpretation and acceptance of some of the results of Huys et al. (2009), pending a detailed redescription of $A$. abyssalis and a revision of the genera Argestigens and Sarsameira.

The problem around Exanechentera Lang 1944

In accordance with Becker (1974), an 8-segmented female A1, with an aesthetasc inserted on the 3rd segment (similar to what can be seen in Parameiropsis) is present in Aegisthidae Giesbrecht, 1892 and in Pontostratiotes Brady, 1883 (a genus formed by at least 27 species) (viz. Bodin 1997). Seifried (2003) considered this character as present in the groundpattern of this family. However, in spite of these similarities, a close phylogenetic relationship between Parameiropsis species and aegisthids is refused based on strong dissimilarities between the mouthparts of both groups. In addition, both taxa are different with respect to segmentation of antennary exopod and the presence of an inner seta on P1 exp-1 in the Aegisthoidea Giesbrecht, 1892 (i.e. Rometidae Seifried and Schminke 2003 and Aegisthidae). In accordance with Seifried (2003), the loss of this seta is an autapomorphy for Syngnatharthra Seifried and Schminke 2003 (formed by all Oligoarthra, without Aegisthoidea). An aesthetasc on the 3rd segment of the female A1 can also be found within Argestidae, namely, in species of Eurycletodes. However, other characters ("Discussion") do not support the proximity of Eurycletodes and Parameiropsis.

An alternative would be to consider the genus Parameiropsis, a member of the Palinarthra Seifried 2003. According to Seifried (2003), the monophyletic condition of this group can be supported by the following autapomorphies: For definition of "lateral element 1", seta 8 and seta 10 see Seifried (2003, p. 114, Fig. 35).

Strongly developed triangular labrum and fused lobes of paragnaths forming an oral cone. Gnathobasis of Md elongated and narrow. Praecoxal arthrite of Mx1 elongated and narrow. Syncoxa of Mxp at most twice as long as wide. Lateral element 1 of distal endopodal segment of A2 forming a seta. Seta 10 of Mx1 praecoxa is absent. Distal endite of Mx2 praecoxa (here interpreted as syncoxa) with 2 setae and fused with the proximal endite. Seta 8 of exp P5 is present.

Parameiropsis could be included in this group based on the first four characters. The other characters are not present in any Parameiropsis species and should be considered lost in a derived group within Palinarthra in order to support the inclusion of this genus. Other characters present in the groundpattern of the Palinarthra, in accordance with Seifried (2003), are not present in Parameiropsis. Here, we can mention the Palinarthra groundpattern for the armature of exp-3 and enp- 3 of P1, with 6 elements and 5 elements, respectively (in the Parameiropsis groundpattern, 5 elements occur in exp-3 and 3 in enp-3 of P1); shape and armature of the Mxp (much more slender and with more setigerous elements in the groups within Palinarthra than in Parameiropsis), and finally, the general armature of the mouthparts (with more elements in Palinarthra than in Parameiropsis). An ad hoc reasoning would favour the inclusion of Parameiropsis as a derived taxon within Palinarthra. Within this scenario, the P1, Mxp and mouthparts would have passed through a process of specialization and loss of setal elements. However, we lack evidence that would reinforce this assumption. Despite the oral cone formation and associated characters, there is a great morphological disparity between the families included into Palinarthra and Parameiropsis. This leads us to believe that 
the similarity of the labrum, mandibular gnathobasis and praecoxal arthrite of Mx1 might well be the result of convergent evolution since this complex of characters appeared independently even in different copepod orders (viz. Siphonostomatoida).

Within Parameiropsis, only P. magnus has a bulge on the mandibular gnathobasis. The latter is considered as a synapomorphy for Exanechentera (Seifried 2003), being absent in only two taxa with stylet-like mandibular gnathobasis. In accordance with Seifried (2003), it is probable that with the extreme elongation of the mandibular gnathobasis and the accompanying functional change, the bulge became a hindrance and therefore was reduced. Finally, Seifried (2003) considered that this structure evolved convergently in a few species of Podogennonta and the ancestral line to Exanechentera. Similarly to some Exanechentera taxa, Parameiropsis has the distal border of A2 enp bevelled with an angle towards the exp (Seifried 2003). However, they do not have any setae on enp-1 of Mxp, which is transformed into a strong claw (maybe seta VI of Seifried 2003), a character credited to Exanechentera by Martínez Arbizu and Moura (1998). Given the low number of P1 armature elements in Parameiropsis, its inclusion even at the basis of this group is not conclusively supported.

In conclusion, there is no synapomorphic evidence to consider Parameiropsis a member of the Ameiridae. On the contrary, there is evidence that the genus does not belong to Podogennonta and that its position within Harpacticoida cannot be satisfactorily established without taking many assumptions into account. Therefore, we propose to accommodate Parameiropsis with all its known species within a new family Parameiropsidae fam. $n$.

Identification Key for the known species of Parameiropsis
1) Exp-3 of P1 with 5 spines/setae ( 3 outer and 2 distal)

$\mathbf{1}^{\prime}$ ) Exp-3 of P1 with 4 spines/setae (2 outer and 2 distal); enp-3 of P1 with an outer spine; loss of the inner setae of the exp-1 of P2-P4; loss of proximalmost outer spine of exp-3 of P2-P4; loss of proximalmost inner seta of enp-3 P3; inner setae of exp-2-3 and enp-1-3 of P2-P4 short

2) Male, mouthparts athrophied; A1 9-segmented, 5th segment is the largest, aesthetasc inserts proximally on the 5th segment and on the 9th segment, 5th segment aesthetasc very long; exp-3 of P1 with 3 outer spines and 2 distal setae

2') Male, mouthparts completely developed; exp-3 of P1 with 3 outer spines, 1 outer distal spine and an inner distal seta; A1 10-segmented, 5th and 6th segments separated, aesthetasc on 5th and 10th segments; furca short, about half the length of the telson, almost 4 times longer than wide; labrum trilobed, with a hyaline membrane around apex, outer lobe of the hyaline membrane with several long setules inserted around its distal half, both P5 medially fused, benp with 2 long spines on the endopodal lobe, exp 1-segmented, as long as broad, with 1 outer seta, 1 long distal spine and 1 inner shorter spine; P6 formed by 2 asymmetrical plates, each armed with 2 setae

2") Female

3) Female; exp-3 of P1 with 2 outer spines, 1 distal spine and 1 distal seta; enp-3 of P1 with an outer bipinnate spine, an outer distal spine and a long inner seta; P5 is a fused plate, benp weakly developed, with 2 long spines on endopodal lobe, exopodal lobe with 2 setae and 1 short inner spine; furca short, 3 times longer than wide, inner margin with a longitudinal row of spinules

$3^{\prime}$ ) Female, exp-3 of P1 with 2 outer spines and 2 spiniform setae distally inserted; enp- 3 of P1 with outer unipinnate spine, spiniform outer distal seta and a small and slender inner terminal seta; P5 not fused medially, benp with 2 endopodal spines inserted apically (inner spine bipinnate and two-times longer than outer spine), exp fused to benp and represented by two outer setae and one long apical; rostrum with a biphid tip; furca narrowed proximally

4) Furca asymmetric, long, left ramus 12 times longer than wide, right ramus 7 times longer than wide; P5 is a fused plate, benp and exp fused, endopodal lobe with 2 strong distal spines and 1 inner seta, exp with 1 outer seta and 2 strong distal spines (outermost longer); P6 formed by 2 asymmetrical plates (largest one on the left side), each armed with 1 outer seta and 1 strong distal spine

$4^{\prime}$ ) Furca symmetrical, at about 6 times longer than wide; anal operculum concave; P5 represented by a fused plate; benp not fused to exp, endopodal lobe with 2 strong distal spines; exp slightly longer than wide, with an outer seta and 2 strong distal spines (outermost is bigger); P6 represented by 2 asymmetrical plates (largest one on the right side), each with an outer seta and a strong distal spine

5) Furca short, almost quadratic

$5^{\prime}$ ) Furca is circa of 4 times longer than broad, almost half the length of the telson; P5 not fused medially, benp not fused to the exp, basenpodal lobe armed with 3 long spines, exp with a long inner spine and two outer setae

6) Enp-3 of P1 with outer unipinnate spine, spiniform outer distal seta and an inner terminal seta as long as the outer distal seta; P5 represented by a fused plate, benp fused to the exp, endopodal lobe with 3 strong distal spines, exopodal lobe with an inner spiniform seta and two outer slender setae

6') P5 not fused medially, benp fused to the exp, endopodal lobe with 3 strong distal spines, exopodal lobe with an inner spiniform seta and two outer slender setae
2

3

4

Parameiropsis poseidonicus sp.n.

5

Parameiropsis amphitriteae sp. n. Parameiropsis
antennafortis

Parameiropsis neptuni sp. n.

Parameiropsis senckenbergi sp.n.

6

Parameiropsis peruanus

Parameiropsis magnus

Parameiropsis rapiens 
Acknowledgments We are indebted to the Census of Marine Life, which financially supported the senior author with a fellowship programme for deep-sea taxonomists. We are also indebted to Gisela Moura for the numerous valuable comments during the initial phase of this work. We would also like to thank Dr. Kai George and Lena Menzel for some valuable ideas. MSc. Vasiliki Kalogeropoulou allowed us to study the Ameiridae and Argestidae from Porcupine Abyssal Plane (PAP). MSc. Radith Mahatma allowed us to study an Anoplosomella species from the Pacific nodule area and MSc. Marco Büntzow gave to access to his Argestidae and Ameiridae material from Sedlo and Seine sea mounts contributing also with valuable comments and exchange of ideas. This work would not have been possible without the extensive work of Dr. H.K. Schminke and his students, who during years compiled all the relevant bibliography of Copepoda. We are indebted to the technical staff of DZMB for sorting the samples and to our secretary Ms. Christa Dohn for her outstanding work and care with Senckenberg guest scientists. Finally, we would like to thank the helpful comments offered by the two anonymous referees.

\section{References}

Becker KH (1972) Eidonomie und Taxonomie abyssaler Harpacticoidea. PhD Thesis, Christian Albrechts Universität

Becker KH (1974) Eidonomie und Taxonomie abyssaler Harpacticoidea (Crustacea, Copepoda). Teil 1. Cerviniidae-Ameiridae. Meteor Forsch Ergebn 18:1-28

Bodin P (1997) Catalogue of the new marine harpacticoid copepods (1997 edition). Doc Trav Inst R Sci Nat Belg 89:1-304

Boeck A (1865) Oversigt over de ved Norges Kyster jagttagne Copepoder henhörende til Calanidernes, Cyclopidernes og Harpactidernes Familier. Forh Vidensk Selsk Krist 1864:226-282

Boeck A (1872) Nye Slaegter og Arter af Saltvands-Copepoder. Forh Vidensk Selsk Krist 1872:35-60

Boxshall G, Halsey SH (2004) An introduction to copepod diversity. Ray Society, London

Brady GS (1880) A monograph of the free and semi-parasitic Copepoda of the British Islands. Ray Society, London

Canu E (1892) Les Copépodes du Boulonnais. Morphologie, embryologie, taxonomie. Trav Lab Zool Mar Wimereux-Ambleteuse 6:1-292

Chappuis PA (1927) Tableaux dichotomiques des genres et espèces d'Harpacticoïdes des eaux douces d'Europe et remarques sur deux travaux parus en 1927. Arch Zool Exp Gen 67:114-128

Conroy-Dalton S, Huys R (1997) Towards a revision of Ameira Boeck, 1865 (Harpacticoida, Ameiridae): re-examination of the A. tenella-group and the establishment of Filexilia gen. n. and Glabrameira gen. n. Zool Scr 25(4):317-339

Corgosinho PHC, Gheerardyn H (2009) A new species of Parameiropsis Becker, 1974 (Copepoda: Harpacticoida) from the Porcupine Seabight (North-East Atlantic Ocean). Mar Biodivers 39(2):8393. doi: $10.1007 / \mathrm{s} 12526-009-0005-8$

Ferrari FD, Ivanenko VN (2008) The identity of protopodal segments and the ramus of maxilla 2 of copepods (Copepoda). Crustaceana 81(7):823-835

Fiers F (1987) Intercletodes interita n. gen., n. sp. and Orthopsyllus coralliophilus $\mathrm{n}$. sp., two new copepods from the northern coast of Papua New Guinea (Copepoda Harpacticoida). Bull Inst R Sci Nat Belg 57:123-132

Fiers F (1990) Abscondicola humesi n. gen, n. sp. from the gill chambers of land crabs and the definition of the Cancrincolidae $\mathrm{n}$. fam. (Copepoda, Harpacticoida). Bull Inst R Sci Nat Belg 60:69-103

George KH (2004) Description of two new species of Bodinia, a new genus incertae sedis in Argestidae Por, 1986 (Copepoda, Harpacticoida), with reflections on argestid colonization of the Great Meteor Seamount plateau. Org Div Evol 4:241-264
George KH (2008) Argestes angolaensis sp. nov. (Copepoda: Harpacticoida: Argestidae) from the Angola Basin (Southeast Atlantic), and the phylogenetic characterization of the taxon Argestes Sars, including the redescription of A. mollis Sars, 1910, and A. reductus (Itô, 1983). Zootaxa 1866:223-262

Gurney R (1932) British fresh-water Copepoda. II. Harpacticoida. The Ray Society, London

Huys R (1990) A new family of harpacticoid copepods and an analysis of the phylogenetic relationships within the Laophontoidea $\mathrm{T}$. Scott. Bijd Dierk 60:79-120

Huys R, Boxshall GA (1991) Copepod evolution. The Ray Society, London

Huys R, Conroy-Dalton S (1997) Discovery of hydrothermal vent Tantulocarida on a new genus of Argestidae (Copepoda: Harpacticoida). Cah Biol Mar 38:235-249

Huys R, Conroy-Dalton S (2006) Revision of the genus Evansula T. Scott, 1906 (Copepoda, Harpacticoida, Cylindropsyllidae) with a description of three new species. Zool J Linn Soc 147(4):419-472

Huys R, Lee W (1998/99) On the relationships of the Normanellidae and the recognition of Cletopsyllidae grad. nov.(Copepoda, Harpacticoida). Zool Anz 237: 267-290

Huys R, Gee JM, Moore CG, Hamond R (1996) Synopses of the British Fauna (New Series) No. 51. Marine and Brackish Water Harpacticoids, Part 1. Field Studies Council, Shrewsbury

Huys R, Mackenzie-Dodds J, Llewellyn-Hughes J (2009) Cancrincolidae (Copepoda, Harpacticoida) associated with land crabs: A semiterrestrial leaf of the ameirid tree. Mol Phylogenet Evol doi:10.1016/j.ympev.2008.12.007

ICZN (1999) International code of zoological nomenclature, 4th edn. International Trust for Zoological Nomenclature, London

Itô T (1983) Harpacticoid copepods from the Pacific abyssal off Mindanao. II. Cerviniidae (cont.), Thalestridae, and Ameiridae. Pub Seto Mar Biol Lab 28(1-4):151-254

Knoop V, Müller K (2009) Gene und Stammbäume: ein Handbuch zur molekularen Phylogenetik (2 Aufl.). Elsevier, Spektrum Akad. Verl., München

Lang K (1936) Beiträge zur Kenntnis der Harpacticiden. 6. Bemerkungen über die Familie der Ameiridae Monard. Zool Anz 114(56): $133-136$

Lang K (1944) Monographie der Harpacticiden (Vorläufige Mitteilung). Almq \& Wiksells, Uppsala

Lang K (1948) Monographie der Harpacticiden, vol 1 and 2. Hakan Ohlsson's Boktryckeri, Lund

Lee W, Huys R (2002) A new genus of groundwater Ameiridae (Copepoda, Harpacticoida) from boreholes in Western Australia, the artificial status of Stygonitocrella Petkovski, 1976. Bull Nat Hist Mus 68(1):39-50

Lilljeborg W (1853) Om de inom Skaane förekommande Crustaceer af ordingarne Cladocera, Ostracoda och Copepoda. De crustaceis ex ordinibus tribus: Cladocera, Ostracoda et Copepoda. Scania Occurrentibus, Lund

Martin JW, Davis GE (2001) An updated classification of the recent Crustacea. Nat Hist Mus Los Angel Cty Sci Ser 39:1-124

Martínez Arbizu P, Moura G (1994) The phylogenetic position of the Cylindropsyllinae Sars (Copepoda, Harpacticoida) and the systematic status of the Leptopontiinae Lang. Zool Beitr 35(1):55-77

Martínez Arbizu P, Moura G (1998) Atergopediidae, a new family of harpacticoid copepods (Crustacea) from oligotrophic Arctic sediments. Zool Beitr 38(2):189-210

McIntyre AD, Warwick RM (1984) Meiofauna techniques. In: Holme NA, McIntyre AD (eds) Methods for the study of marine benthos. Blackwell, Oxford

Menzel L, George KH (2009) Description of four new species of Mesocletodes Sars, 1909 (Copepoda, Harpacticoida, Argestidae) and redescription of Mesocletodes robustus Por, 1965 from the 
South Atlantic, including remarks on the phylogeny of the Mesocletodes abyssicola-group. Zootaxa 2096:214-256

Monard A (1927) Synopsis universalis generum Harpacticoidarum. Zool Jahrb Abt Syst 54(1-2):139-176

Por FD (1986) A re-evaluation of the family Cletodidae Sars, Lang (Copepoda, Harpacticoida). Syllogeus 58:420-421

Sars GO (1906) Copepoda Harpacticoida. Parts XV and XVI. Diosaccidae (concluded), Canthocamptidae (part). An Account of the Crustacea of Norway, with short descriptions and figures of all the species. Berg Mus 5:173-196

Sars GO (1907) Copepoda Harpacticoida. Parts XIX and XX. Canthocamptidae (concluded), Laophontidae (part). An account of the Crustacea of Norway, with short descriptions and figures of all the species. Berg Mus 5:221-240

Schminke HK (1976) The ubiquitous telson and the deceptive furca. Crustaceana 30:292-300

Scott A (1909) The Copepoda of the Siboga Expedition (Part I). Freeswimming, littoral and semi-parasitic Copepoda. Siboga Expeditie, Monograph 29a: 1-323
Seifried S (2003) Phylogeny of Harpacticoida (Copepoda): revision of 'Maxillipedasphalea' and Exanechentera. Cuvillier Verlag, Göttingen

Seifried S, Schminke HK (2003) Phylogenetic relationships at the base of Oligoarthra (Copepoda, Harpacticoida) with a new species as the cornerstone. Org Div Evol 3:13-37

Wägele J-W (2005) Foundations of phylogenetic systematics. Verlag Dr Friedrich Pfeil, München

Wells JBJ (2007) An annotated checklist and keys to the species of Copepoda Harpacticoida (Crustacea). Zootaxa, Auckland

Willen E (2000) Phylogeny of the Thalestridimorpha Lang, 1944 (Crustacea, Copepoda). Cuvillier Verlag, Göttingen

Willen E (2002) Notes on the systematic position of the Stenheliinae (Copepoda, Harpacticoida) within the Thalestridimorpha and description of two new species from Motupore Island, Papua New Guinea. Cah Biol Mar 43(1):27-42 